This Health Hazard Evaluation (HHE) report and any recommendations made herein are for the specific facility evaluated and may not be universally applicable. Any recommendations made are not to be considered as final statements of NIOSH policy or of any agency or individual involved. Additional HHE reports are available at http://www.cdc.gov/niosh/hhe/reports

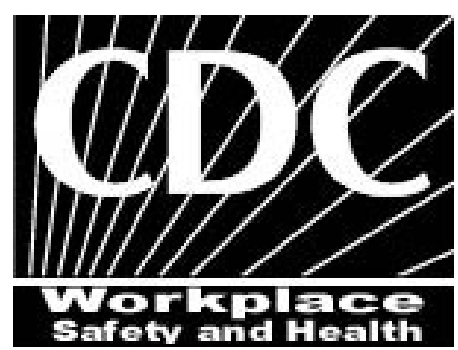

NIOSH HEALTH HAZARD EVALUATION REPORT:

HETA \#99-0260-2906

Marx Industries, Inc.

Sawmills, North Carolina

\title{
June 2003
}

DEPARTMENT OF HEALTH AND HUMAN SERVICES

Centers for Disease Control and Prevention

National Institute for Occupational Safety and Health

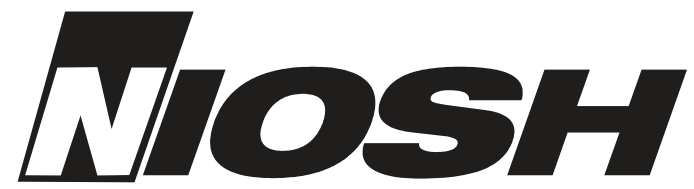




\section{PREFACE}

The Hazard Evaluations and Technical Assistance Branch (HETAB) of the National Institute for Occupational Safety and Health (NIOSH) conducts field investigations of possible health hazards in the workplace. These investigations are conducted under the authority of Section 20(a)(6) of the Occupational Safety and Health (OSHA) Act of 1970, 29 U.S.C. 669(a)(6) which authorizes the Secretary of Health and Human Services, following a written request from any employer or authorized representative of employees, to determine whether any substance normally found in the place of employment has potentially toxic effects in such concentrations as used or found.

HETAB also provides, upon request, technical and consultative assistance to Federal, State, and local agencies; labor; industry; and other groups or individuals to control occupational health hazards and to prevent related trauma and disease. Mention of company names or products does not constitute endorsement by NIOSH.

\section{ACKNOWLEDGMENTS AND AVAILABILITY OF REPORT}

This report was prepared by Josh Harney, Jeffrey Nemhauser, Chris Reh, and Doug Trout of HETAB, Division of Surveillance, Hazard Evaluations and Field Studies (DSHEFS), and Steve Schrader of the Division of Applied Research and Technology (DART). Field assistance was provided by Greg Burr, Aaron Sussell, and Dino Mattorano of HETAB. Paul Dowdy, Registered ElectroDiagnostic Technician, performed our nerve conduction studies. Interpretation of nerve conduction studies was performed by Mark J. Goddard, MD, University of Cincinnati Department of Physical Medicine and Rehabilitation. Analytical support was provided by Datachem Laboratories. Desktop publishing was performed by Ellen Blythe, David Butler, and Pat McGraw. Review and preparation for printing were performed by Penny Arthur.

Copies of this report have been sent to employee and management representatives at Marx Industries, Inc. and the OSHA Regional Office. This report is not copyrighted and may be freely reproduced. Single copies of this report will be available for a period of three years from the date of this report. To expedite your request, include a self-addressed mailing label along with your written request to:

\section{NIOSH Publications Office \\ 4676 Columbia Parkway \\ Cincinnati, Ohio 45226 \\ 800-356-4674}

After this time, copies may be purchased from the National Technical Information Service (NTIS) at 5825 Port Royal Road, Springfield, Virginia 22161. Information regarding the NTIS stock number may be obtained from the NIOSH Publications Office at the Cincinnati address.

For the purpose of informing affected employees, copies of this report shall be posted by the employer in a prominent place accessible to the employees for a period of 30 calendar days. 


\section{Highlights of the NIOSH Health Hazard Evaluation}

\section{Evaluation of Exposure to Spray Adhesive (1-bromopropane [1-BP])}

This Health Hazard Evaluation was requested by the North Carolina Department of Labor to address concerns about possible health problems related to working with a spray adhesive that contains the chemical 1bromopropane [1-BP]. We also checked to see if Marx employees were exposed to arsenic.

\section{What NIOSH Did}

- We checked the air for 1-BP levels.

- We took air, water, hand wipe, and surface dust samples to try to find any arsenic source.

- We asked employees to fill out a questionnaire and participate in a medical survey.

- We conducted a medical survey to see if exposure to 1-BP at Marx was causing problems with blood counts, nerve problems, and, for men, reproductive problems.

\section{What NIOSH Found}

- Employees on the spray lines were exposed to high levels of 1-BP.

- The wall fans near spray tables don't lower 1-BP levels enough.

- Some Marx workers were having symptoms of headache and feeling "drunk" that might have been related to overexposure to 1-BP.

- We did not find evidence that 1-BP exposure caused nerve or reproductive problems, or problems with blood counts.

- Many spray line employees had increased levels of arsenic in their urine, but we did not find any exposure to arsenic at Marx.

\section{What Marx Managers Can Do}

- Lower worker exposures to 1-BP by switching to water-based spray glue, or by making ventilated spray booths that enclose the spray tables and exhaust the 1-BP to the outdoors.

- Make sure glue sprayers are protected from skin contact with the glue.

- Train employees on health and safety issues related to 1-BP and on proper use of equipment so that exposure to 1-BP can be minimized.

- Re-evaluate employee exposures to 1-BP after attempts to decrease 1-BP exposure have been made.

\section{What Marx Employees Can Do}

- Attend all training and education sessions given by the management

- Follow instructions on proper use of the adhesive spray equipment and any equipment designed to decrease exposure to 1-BP, including spraying only the smallest amount of glue that still makes a good cushion.

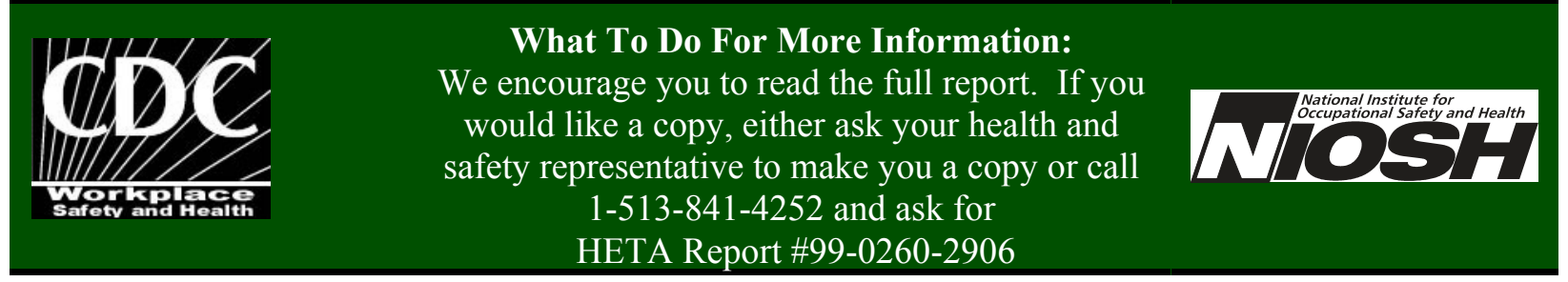

Health Hazard Evaluation Report 99-0260-2906 


\title{
Marx Industries, Inc. Sawmills, North Carolina June 2003
}

\author{
Joshua M. Harney, MS \\ Jeffrey B. Nemhauser, MD \\ Christopher M. Reh, PhD, CIH \\ Douglas Trout, MD, MHS \\ Steve Schrader, PhD
}

\section{SUMMARY}

In April 1999, the North Carolina Department of Labor (NCDOL), Occupational Safety and Health Division, responded to reports that four employees of Marx Industries, Inc., in Sawmills, North Carolina, had been treated at a local hospital. All four had been evaluated for neurologic symptoms of an unclear cause. Hospital laboratory testing reportedly revealed each to have had elevated levels of bromide ion $(\mathrm{Br})$ in blood and arsenic in urine. A NCDOL investigation found no evidence of occupational exposure to arsenic at Marx. Because of concern that worker exposure to 1-bromopropane (1-BP) (and/or possibly arsenic) at Marx was related to observed health effects, NCDOL submitted a request to the National Institute for Occupational Safety and Health (NIOSH) for a health hazard evaluation (HHE).

On November 16-17, 1999, NIOSH investigators conducted an initial site visit, and measured 1-BP and 2-bromopropane (2-BP, also known as isopropyl bromide, found as a contaminant of 1-BP formulations) inhalation exposures to employees working in and near the adhesive spray operations. An additional inhalation exposure assessment was conducted on January 29, 2001. A medical evaluation was performed in January/February 2001 and consisted of (1) a questionnaire survey, (2) collection of blood for a complete blood count $(\mathrm{CBC})$ and to measure whole blood and serum Br concentrations, (3) collection of urine to measure urine $\mathrm{Br}$ and arsenic concentrations, (4) nerve conduction testing, and (5) an evaluation of the male reproductive system. NIOSH representatives further investigated potential sources of arsenic exposure at Marx on May 23, 2001.

Data from 16 full-shift personal breathing zone (PBZ) samples for 1-BP during the November 1999 exposure assessment (geometric mean [GM] $81.2 \mathrm{ppm}$; range 18 - $254 \mathrm{ppm}$ ) and from 13 full-shift PBZ samples during the January 2001 assessment (GM 45.7 ppm; range $7-281 \mathrm{ppm}$ ) revealed that most spray-line workers were exposed to 1-BP at concentrations above proposed $25 \mathrm{ppm}$ exposure guidelines during both exposure assessments. PBZ concentrations of 1-BP were lower in January 2001 compared to November 1999, although the difference was not statistically significant. Among unexposed workers (assessed only during the January 2001 survey), none had 1-BP exposures exceeding $5 \mathrm{ppm}$ (GM $1.1 \mathrm{ppm}$; range $0.1-4.9 \mathrm{ppm}$ ). Area air sampling in areas adjacent to the spray lines during both surveys found low concentrations of 1-BP, indicating that 1-BP vapors were migrating from the spraying operations. 2-BP concentrations in air were found to be low in both exposure assessments.

Forty-three ( $72 \%$ of the 60 workers) persons participated in the questionnaire survey, including 13 workers exposed to 1-BP and 30 workers unexposed. Among these 43, end-of-week and start-of-week serum and urine $\mathrm{Br}$ and whole blood $\mathrm{Br}$ concentrations were statistically significantly greater among the exposed group compared to the unexposed group, and all were correlated with individual PBZ 1- BP air concentrations. 
Among the symptoms assessed in the questionnaire survey were symptoms consistent with nonspecific effects of exposure to bromine and/or solvents. Headache was the symptom reported by the most workers ( 22 workers). We found that symptoms of anxiety (nervousness), feeling drunk, and headache were associated with exposure to 1-BP. Other evaluated symptoms (such as trouble concentrating) were not related to exposure.

Forty workers had blood samples analyzed for a CBC. All measures of red blood cells, hemoglobin, and platelets were within the normal ranges provided by the laboratory; one person (unexposed to 1-BP) had a white blood cell count slightly below the lower end of the normal range provided by the laboratory. There were no statistically significant differences in the medians of these parameters between the exposed and unexposed workers and we found no statistically significant relationships between exposure (increasing 1-BP PBZ air or urine $\mathrm{Br}$ concentrations) and individual cell counts or hemoglobin concentration.

None of the workers completing the questionnaire responded that they had a doctor-diagnosed reproductive or infertility problem. Nine men (50\% of the 18 male participants) participated in the laboratory evaluation of male reproductive function, including three exposed workers. Five of the nine men had an abnormal semen analysis; four of these five were unexposed to 1-BP. Analyses to evaluate relationships between measures of exposure (including 1-BP PBZ air concentration and end-of-week urine Br concentration) and the three sperm indices (shape, motility, and number) revealed no evidence of a statistically significant correlation.

Forty-two (98\%) of the forty-three participants had nerve conduction studies performed. The one worker who did not have nerve conduction testing was unexposed. Of the 42, five (12\%) were abnormal. Among the 5 workers with abnormal tests, 2 were among the 13 workers exposed to 1-BP, although neither were sprayers. The prevalence ratio (PR) for an abnormal nerve conduction test among exposed workers was 1.5 (95\% confidence interval 0.3 - 7.9). PBZ exposure to 1-BP and end-of-week urine Br concentration were higher among persons with normal nerve conduction testing, although the differences were not statistically significant.

Forty-one participants provided urine specimens that were analyzed for total inorganic arsenic. Twelve workers had levels of inorganic arsenic above $25 \mu \mathrm{g} / \mathrm{g}$ creatinine; ten (83\%) of those twelve workers had jobs near or on the Springs and Glue Lines. As a result of these data and previous concern about arsenic exposure at Marx, in May 2001 NIOSH investigators conducted a thorough examination of the Marx workplace for a source of arsenic. No arsenic was detected in any of the air, bulk adhesive, or drinking water samples collected during that evaluation. Of the 30 surface wipe samples collected from around the plant, one (collected on the concrete surface of the loading dock) had a detectable quantity of arsenic on it.

In this HHE we found inadequate controls of 1-BP exposure and a potential health hazard among employees exposed to 1-BP. Most workers on the adhesive application lines were exposed to 1-BP at concentrations above $25 \mathrm{ppm}$, and some were exposed to much higher concentrations. These results suggest that the spray-line exhaust fans in place at Marx at the time of the HHE were not adequately capturing the 1-BP vapors generated during the spray adhesive operations. Data from the questionnaire survey suggest that excessive exposure to 1-BP among HHE participants may be related to acute symptoms (such as anxiety [nervousness], feeling drunk, and headache) that have been associated with excessive exposure to bromine or to other types of solvents. We found no evidence for other health effects related to occupational exposure to 1-BP among persons working at Marx during the time of our evaluation.

Where NIOSH has conducted surveys in other foam fabrication facilities, implementation of recommended engineering controls has successfully reduced inhalational exposure to 1-BP. Recommendations are made in this report to assist Marx Industries in accomplishing similar results. 
We found no source of arsenic at Marx and conclude that occupational exposures at Marx are not likely to account for the elevated urinary arsenic levels found among employees.

KEYWORDS: SIC Code 2392 (House furnishing, Except Curtains and Draperies) 1-bromopropane, 1-BP, npropyl bromide, 2-BP, 2-bromopropane, isopropyl bromide, arsenic, nerve conduction tests, bromine, reproductive problems, semen analysis, sperm analysis, complete blood count, solvent. 


\section{TABLE OF CONTENTS}

Preface

Acknowledgments and Availability of Report $\ldots \ldots \ldots \ldots \ldots \ldots \ldots \ldots \ldots \ldots \ldots \ldots \ldots \ldots \ldots \ldots \ldots$

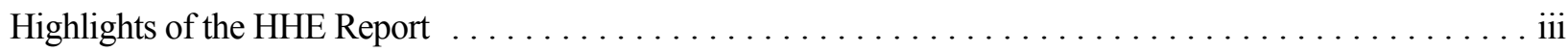

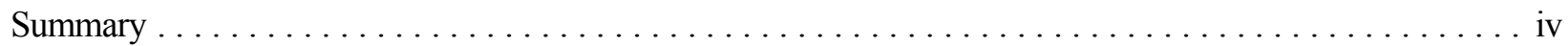

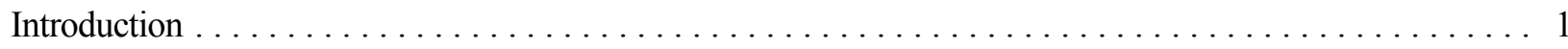

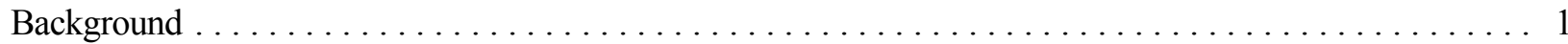

Review of Medical Records . . . . . . . . . . . . . . . . . . . . . . . . . . . . . 1

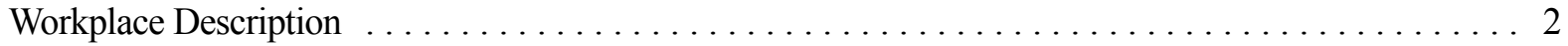

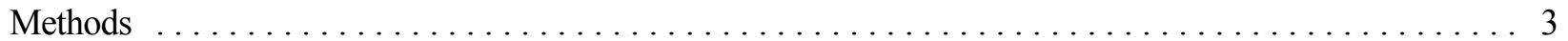

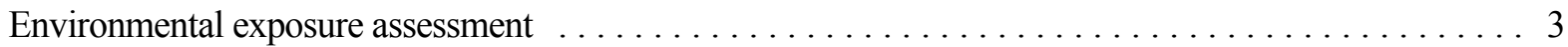

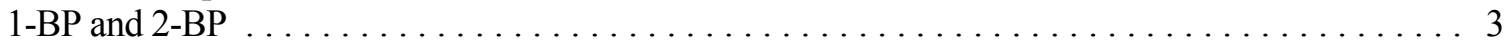

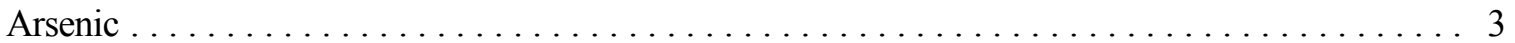

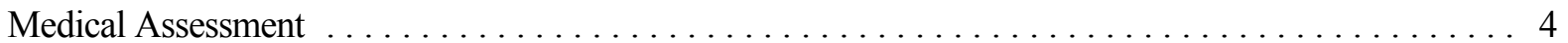

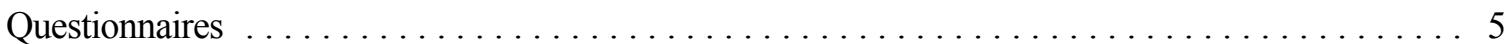

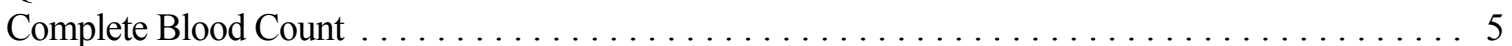

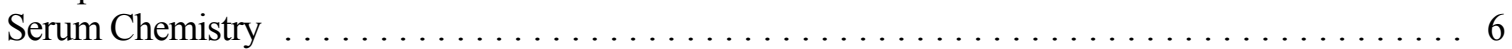

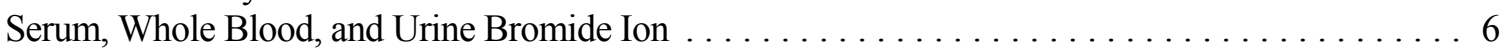

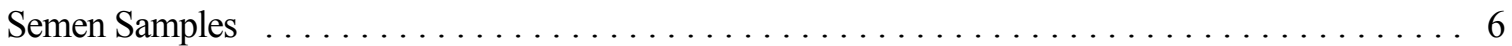

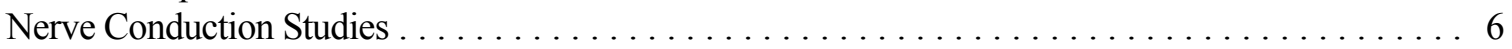

Urinary Arsenic Levels . . . . . . . . . . . . . . . . . . . . . . . . 7

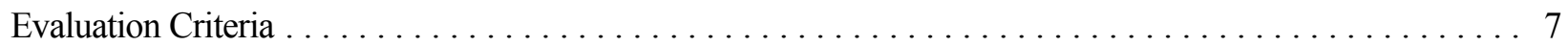

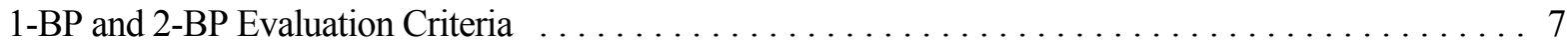

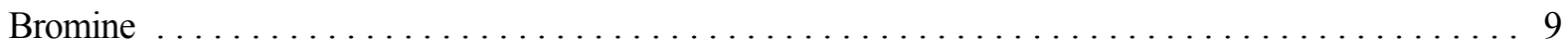

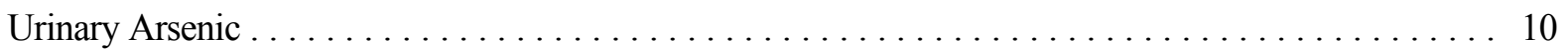

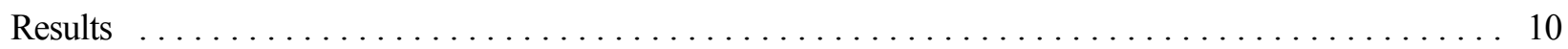

November 1999: Initial 1-BP and 2-BP Exposure Assessment and Medical Evaluation $\ldots \ldots \ldots \ldots 10$

January 2001: Second 1-BP and 2-BP Exposure Assessment $\ldots \ldots \ldots \ldots \ldots \ldots \ldots \ldots \ldots \ldots$

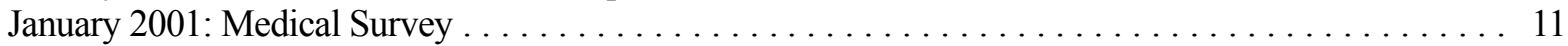

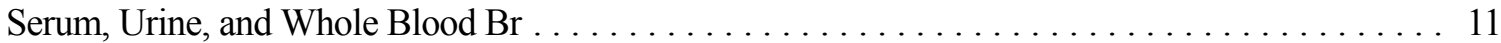

Questionnaires - Questions Concerning Possible Excessive Exposure to Solvent $\ldots \ldots \ldots \ldots \ldots 12$

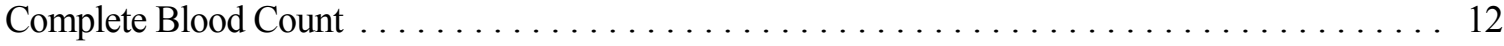

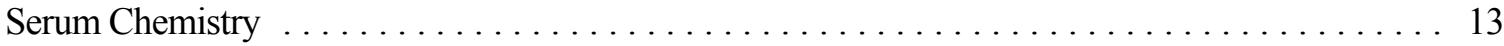

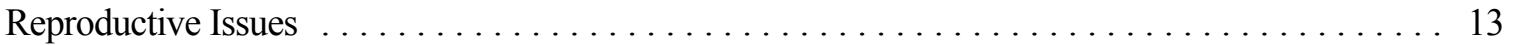

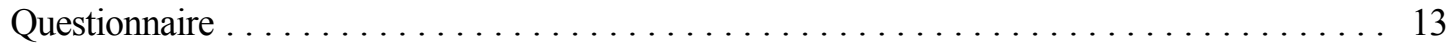

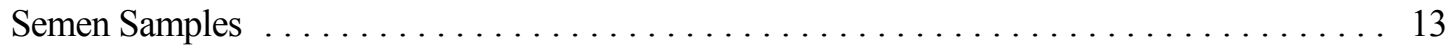

Nerve Conduction Studies . . . . . . . . . . . . . . . . . . . . . . . . 14

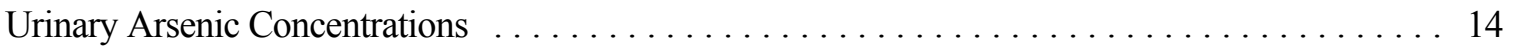

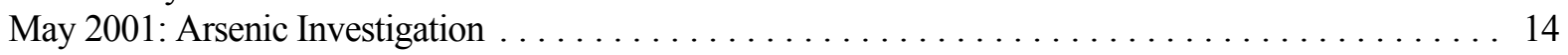




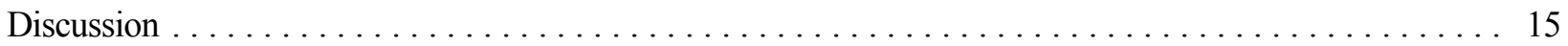

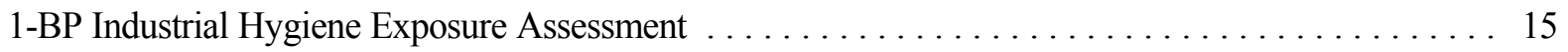

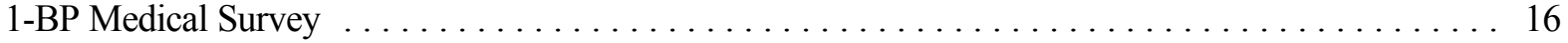

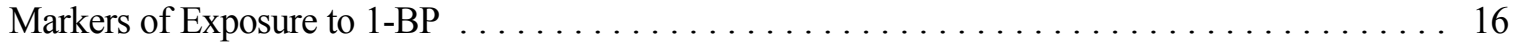

Bromism and Questionnaire Assessment of Solvent-Related Symptoms . . . . . . . . . . . 17

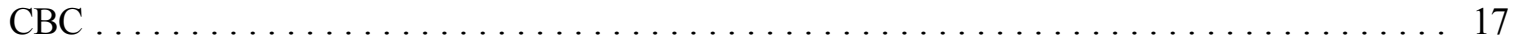

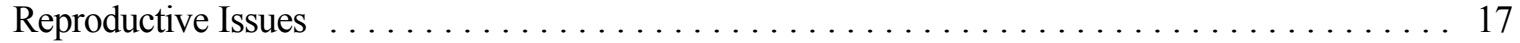

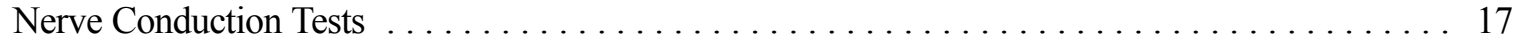

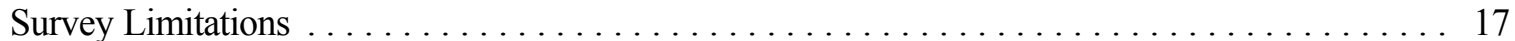

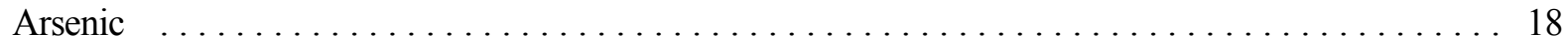

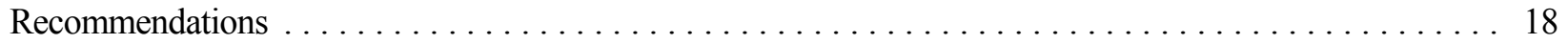

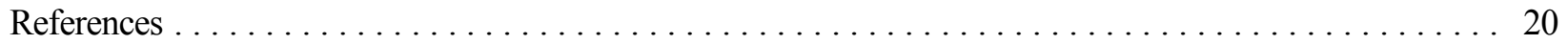




\section{INTRODUCTION}

In April 1999, the North Carolina Department of Labor (NCDOL), Occupational Safety and Health Division responded to reports of four employees of Marx Industries, in Sawmills, North Carolina, who had been treated at local hospitals in March 1999. All four had been evaluated for neurologic symptoms of uncertain etiology. Hospital laboratory testing revealed each to have had elevated levels of bromide ion $(\mathrm{Br})$ in blood and arsenic in urine. Based on these findings, an investigator from NCDOL visited Marx Industries to collect air, wipe, water, and bulk samples for arsenic. No arsenic was detected in any sample collected by NCDOL. Because of concern that workers may have had occupational exposures to $\mathrm{Br}$ and/or arsenic in their work at Marx Industries, in June 1999 NCDOL submitted a request to the National Institute for Occupational Safety and Health (NIOSH) for a health hazard evaluation (HHE). In the request, NCDOL was specifically concerned about occupational exposures to the solvent 1-bromopropane (1-BP, also known as n-propyl bromide) during the spray application of adhesives. 1-BP is a solvent recently introduced for use in the United States and is the primary solvent vehicle for the adhesive used in the manufacturing processes at Marx Industries.

On November 16-17, 1999, NIOSH investigators conducted an initial site visit to Marx Industries. At that time, the plant had been using adhesives formulated with 1-BP for approximately one year. NIOSH investigators spoke with management and employee representatives, reviewed the company's Occupational Safety and Health Administration (OSHA) Log and Summary of Occupational Injuries and Illnesses ("200 Logs"), and interviewed available employees whose names appeared on the OSHA log as having had an "adhesive exposure related illness" within the previous year. In addition, $\mathrm{NIOSH}$ investigators measured 1-BP and 2-bromopropane (2-BP, also known as isopropyl bromide) exposures to workers in and near the adhesive spray operations. An additional inhalation exposure assessment was conducted on January 29,
2001, in conjunction with a medical survey. The medical evaluation was performed in January/February 2001 and consisted of a questionnaire survey; collection of blood and urine to determine complete blood counts (CBC), serum, urine, and whole blood $\mathrm{Br}$ concentrations, and urine arsenic concentrations; nerve conduction testing; and an evaluation of the male reproductive system. Because urine arsenic concentrations collected during the medical evaluations raised concerns regarding the presence of an unidentified source of arsenic within the plant, investigators from NIOSH returned to Marx Industries on May 23, 2001, to further investigate potential sources of arsenic exposure within the workplace.

A letter summarizing the results of the November 1999 industrial hygiene data was distributed to management and employee representatives on February 1, 2000. In April 2001 employees were notified of their individual urinary arsenic levels from the tests performed during the week of January 29,2001 . In a letter to management and employee representatives dated April 16, 2001, NIOSH also provided a summary of the results of that arsenic testing. Letters to individual employees presenting the remaining results of their medical tests were distributed in June 2001. A letter to management and employee representatives summarizing the May 23, 2001, site visit to Marx was distributed on October 3, 2001. The North Carolina State Department of Health and the NCDOL were advised by telephone of data concerning potential arsenic exposure immediately after data were analyzed.

\section{BACKGROUND}

\section{Review of Medical Records}

A review of available medical records for the hospitalized Marx Industries employees (two of whom were working at Marx at the time of the initial site visit) revealed that all four had been hospitalized in March 1999 for similar neurological complaints: lightheadedness and/or dizziness, lower extremity weakness, varying degrees of difficulty standing or walking (ataxia), and varying degrees of bilateral 
lower extremity numbness or paresthesias. Each employee had had these symptoms for variable lengths of time (ranging from approximately two weeks to two months) prior to their hospital admission. One employee also described visual hallucinations at that time. Three of the four had worked at Marx Industries for at least three years as foam cushion fabricators; the fourth had only recently been hired at the facility as a foam cushion fabricator. Each attributed their symptoms to an occupational exposure.

On admission, all four hospitalized employees were found to have elevated serum $\mathrm{Br}$ concentrations ( 77 milligrams per deciliter $[\mathrm{mg} / \mathrm{dL}] ; 53 \mathrm{mg} / \mathrm{dL} ; 100$ $\mathrm{mg} / \mathrm{dL} ; 24 \mathrm{mg} / \mathrm{dL}$ ). Three of four employees also had elevated urinary arsenic concentrations identified at admission (224 micrograms per liter $[\mu \mathrm{g} / \mathrm{L}] ; 200$ $\mu \mathrm{g} / \mathrm{L} ; 318 \mu \mathrm{g} / \mathrm{L}$ ); the fourth employee was subsequently identified as having an elevated urinary arsenic level following discharge from the hospital $(224 \mu \mathrm{g} / \mathrm{L})$. Ultimately, all four of the hospitalized Marx Industries employees carried a diagnosis of (and were treated for) both $\mathrm{Br}$ and arsenic intoxication.

\section{Workplace Description}

At the time of the initial NIOSH site visit (November 1999), Marx Industries employed approximately 80 workers in the manufacture of foam cushions for sofas and other upholstered seating furniture. At the time of the return site visit in January/February 2001, there were approximately 60 persons working at the plant. Cushion manufacture is also referred to as foam fabrication. Workers apply a spray adhesive to variously-shaped pieces of flexible foam and then press the pieces together by hand. The adhesive is applied to the foam by means of a siphon-cup feed, compressed air spray gun. The solvent vehicle for the spray adhesive is 1-BP. Although 1-BP is the primary solvent constituent, small amounts of 2-BP are found in many 1-BP formulations."

*Bulk sampling of the two adhesive formulations used at Marx during the course of the HHE revealed that the formulations contained (by weight): $58 \% 1$ 1-BP
Marx Industries employs workers on two separate foam fabrication lines where the 1-BP-containing adhesive is spray applied: the Springs Line and the Glue Line. The Springs Line consists of four spray tables. Three of these tables are designed to accommodate two sprayers, while the fourth table is designed for only one sprayer. A mechanical conveyor belt, on which assembled cushions are placed, runs alongside the spray tables and separates the tables from an outside wall. Completed cushions are placed on the conveyor belt by Springs Line employees and are then collected by a doffer who bundles the cushions into a complete order in preparation for shipping. Four exhaust fans are located in the outside wall along which the conveyor belt runs. These fans were installed in the late winter/early spring of 1999 to facilitate vapor removal after some employees on the foam fabrication lines had begun to experience adverse health effects. At one time, the Springs Line included an extra spray table (designed for two sprayers) located in the same area but away from the conveyor belt. By January 2001 this table was no longer in use.

The Glue Line, similar in design to the Springs Line, is located in a different room. The Glue Line has five spray tables, with three being designed to accommodate two sprayers, and two designed for a single sprayer. As on the Springs Line, a conveyor belt separates the spray tables from an outside wall. The three exhaust fans on the wall opposite the spray tables on the Glue Line were installed at the same time as were the fans on the Springs Line.

\section{METHODS}

\section{Environmental exposure assessment}

and $0.135 \%$ 2-BP (Imperial Adhesive); and $68.5 \% 1$ BP and $0.0265 \%$ 2-BP (Mid-South Adhesive). The current (ASTM) International standard for 2-BP contamination of neat $1-\mathrm{BP}$ is $0.1 \%$; the industry average, however, ranges from $0.02 \%$ to $0.03 \%$. 


\section{1-BP and 2-BP}

In the course of the two exposure assessments, all workers on the Springs and Glue Lines were targeted for full-shift 1-BP and 2-BP personal breathing zone (PBZ) air sampling. Worker participation in this study was voluntary. Area air sampling was conducted at operations near these lines to determine the extent of 1-BP and 2-BP vapor migration. Air sampling was conducted using a NIOSH draft analytical method for 1-BP and 2-BP. In this method, air is drawn through a standard charcoal tube (SKC Anasorb ${ }^{\circ}$ CSC) at a nominal flowrate of 50 to 100 milliliters per minute $(\mathrm{mL} / \mathrm{min})$ using a calibrated personal sampling pump. For the PBZ air sampling, the sampling pumps and sample trains were worn by the subjects for the entire work-shift; the sample media (charcoal tubes) were placed in the subjects' breathing zones.

After sampling, the charcoal tubes were capped and shipped refrigerated to the analytical laboratory. The front and back sections of the charcoal tubes were placed in glass vials, and each section was desorbed for 30 minutes with one $\mathrm{mL}$ of carbon disulfide. Each sample was analyzed for 1-BP and 2-BP using gas chromatography with a flame ionization detector.

For the bromopropane exposure assessment conducted during November 1999, the 1-BP limit of detection (LOD) and limit of quantification (LOQ) for the draft NIOSH method were 0.9 micrograms per sample $(\mu \mathrm{g} / \mathrm{sample})$ and $3 \mu \mathrm{g} /$ sample, respectively. The LOD and LOQ for 2-BP were 2 and $6 \mu \mathrm{g} / \mathrm{sample}$, respectively. LODs and LOQs are values determined by the analytical procedure used to analyze the samples, and are not dependent on sample volume. Minimum detectable concentrations (MDCs) and minimum quantifiable concentrations (MQCs) are determined by dividing the LODs and LOQs by air sample volumes appropriate for the given set of samples. In determining the MDC and MQC for these exposure data, the NIOSH industrial hygienist used the highest sample volume collected during this survey (24.7 liters[L]). This results in a 1-BP MDC and MQC of 0.007 and 0.02 parts per million (ppm), and a 2-BP MDC and MQC of 0.02 and $0.05 \mathrm{ppm}$. The MDC and MQC reflect the sensitivity of the air sampling and analysis protocol, that is, the lowest 1-BP and 2-BP exposure concentrations that could be reliably detected and quantified by the procedures used in this study.

The purpose of the follow-up bromopropane exposure assessment in January 2001 was to provide current exposure information for those workers participating in the medical survey. Additionally, the second exposure assessment was more comprehensive in that it included employees working on the spray lines as well as employees working away from the spray lines. During this second bromopropane exposure assessment, the personal sampling pumps were calibrated at $100 \mathrm{~mL} / \mathrm{min}$. The LOD and LOQ for 1-BP were $1 \mu \mathrm{g} /$ sample and $3 \mu \mathrm{g} / \mathrm{sample}$, respectively. This translates into an MDC and MQC of $0.004 \mathrm{ppm}$ and $0.01 \mathrm{ppm}$, respectively, when using a sample volume of $50.6 \mathrm{~L}$, the highest sample volume collected during this exposure assessment. The LOD and LOQ for 2-BP were $0.8 \mu \mathrm{g} / \mathrm{sample}$ and $3 \mu \mathrm{g} / \mathrm{sample}$, respectively. This yields an MDC of $0.003 \mathrm{ppm}$ and an MQC of $0.01 \mathrm{ppm}$, based upon the same sample volume.

\section{Arsenic}

The May 2001 site visit was conducted specifically to evaluate the potential for arsenic exposure among Marx employees. During this site visit, NIOSH representatives collected 18 air samples, 30 wipe samples (Ghost Wipes ${ }^{\circledR}$ ) of many work surfaces, 17 bulk samples of materials used during the workday, and four drinking water samples from different sources within the plant. The air, wipe, and bulk samples were analyzed according to NIOSH Method 7300 , with modifications made for each respective matrix. ${ }^{1}$

The air samples were collected onto mixed cellulose ester filters in $37 \mathrm{~mm}$ cassettes using air sampling pumps calibrated at a nominal flow rate of $3 \mathrm{~L} / \mathrm{min}$. The LOD and LOQ, were $0.9 \mu \mathrm{g} / \mathrm{sample}$ and 3 $\mu \mathrm{g} /$ sample, respectively. Based on a sample volume of $1400 \mathrm{~L}$, this yielded a minimum detectable arsenic concentration of 0.6 micrograms per cubic meter of $\operatorname{air}\left(\mu \mathrm{g} / \mathrm{m}^{3}\right)$. 
Among the 18 air samples for arsenic were three PBZ samples and 15 general area samples. A Springs Line sprayer, a Glue Line sprayer, and a utility worker each provided a PBZ sample. The area samples were collected from the following locations: the break room, Springs Line (3 samples), pattern cutting, near the shredder, foam cutting (2 samples), Glue Line (2 samples), 'hand cutting' area near the Glue Line, at the cutting table, outside the north side of the Marx Industries building near the veneer building, 'blow \& fill,' and outside near the loading dock.

Thirty wipe samples were collected for arsenic. The LOD and LOQ were $8 \mu \mathrm{g} / \mathrm{sample}$ and $30 \mu \mathrm{g} / \mathrm{sample}$, respectively. Morning and afternoon hand wipe samples were collected from five workers at the Glue Line, and three workers at the Springs Line. Two NIOSH investigators submitted hand wipe samples at the same times for comparison purposes. Ten wipe samples were collected from the following areas: Springs Line spray table, Springs Line saw table, Glue Line spray table; exhaust fan near Glue Line Parabound M-295 siliconerelease agent, Husky 525 lotion from Glue Line, vending room table top, settled dust from gas heater near Glue Line, sewing departmentbreak table, and the loading dock near the Glue Line.

Bulk samples of solid and liquid materials present in the workplace were also collected and submitted for arsenic analysis. The solid bulk sample analysis had an LOD and LOQ of 3 micrograms per gram $(\mu \mathrm{g} / \mathrm{g})$ and $10 \mu \mathrm{g} / \mathrm{g}$, respectively. For the liquid bulks, the LOD and LOQ were $80 \mu \mathrm{g} / \mathrm{L}$ and $300 \mu \mathrm{g} / \mathrm{L}$, respectively. Solid and liquid bulk samples included the following: Mid South \#6464 adhesive (from Glue Line supply barrel and a spray gun); Mid South \#6464 adhesive (from Springs Line supply barrel and a spray gun); red kerosene-based spray gun cleanser; white battening material; foams P180-27, P180-33, 1122B (blue), P1545, H1A80-27, and P1530; Loshun yellow hand cream; brown paper from spray table coverings; and TACC T-285 Hi Yield spray adhesive (an adhesive used in the past at Marx).

Drinking water samples from the sewing bags room drinking fountain, the drinking fountain by the ramp down to the Springs Line, the sink by the four bathrooms in the rear loading dock between the Springs and Glue Lines, and the office water cooler were also collected for arsenic analysis. The samples were cooled and shipped overnight to be analyzed by US Environmental Protection Agency (EPA) method $6010 .^{2}$ The LOD and LOQ for this method were 2 $\mu \mathrm{g} / \mathrm{L}$ and $7 \mu \mathrm{g} / \mathrm{L}$, respectively.

\section{Medical Assessment}

As part of the initial survey conducted in November 1999, a NIOSH medical officer reviewed the OSHA $200 \log$ and spoke with 4 of the 10 employees whose names appeared in the logs as having had illness related to their exposure to the adhesive containing 1-BP. 1-BP is a solvent which has has had increasing use for industrial applications in recent years; there is limited published information concerning potential health effects related to occupational exposure to 1-BP. The primary goal of the overall medical assessment was to evaluate workers for health effects potentially related to occupational exposure to 1-BP. We included an assessment of exposure to arsenic in our protocol to provide follow-up information to the 1999 NCDOL survey. The protocol for this evaluation was approved by the NIOSH Human Subjects Review Board.

Based on job title and description of duties, we identified those Marx employees who regularly work on or near the lines where spray adhesive was applied (the Springs and Glue Lines). For the purposes of this investigation, those workers were classified as being exposed to 1-BP. The environmental and biological sampling results of this group of workers were compared to those from the group of workers who do not regularly work on or near the Springs and Glue Lines. This second group of workers was classified as being unexposed to 1-BP. PBZ air concentrations of 1-BP from the January 2001 industrial hygiene assessment were used as measures of personal exposure for many of the analyses of the medical and biologic monitoring data. 
Data analyses were done with SAS version 8.12. The prevalence of symptoms among the exposed and unexposed workers was assessed by the prevalence ratio (PR); a 95\% confidence interval $(95 \% \mathrm{CI})$ which excluded one, or a significance level of $\mathrm{p} \leq$ 0.05 , indicates a statistically significant finding. The PR represents the prevalence of the symptom in the exposed group (workers on or near a foam fabrication line) relative to the prevalence in the unexposed group (other workers). A PR of one means there is no association between the symptom/illness and exposure. A PR of greater than one indicates that there is evidence of an association. For example, a PR of two would mean that a person in the exposed group may be twice as likely to have reported the symptom than a person in the unexposed group. The assessment of the differences between two groups of data was done with the t-test (for normally distributed data) and the Wilcoxon twosample test (for data not normally distributed). Correlation between the various biologic measures of exposure was assessed by using the Spearman correlation coefficient.

\section{Questionnaires}

Participants were recruited from the 60 employees at Marx Industries during meetings conducted by NIOSH representatives on the morning of Thursday, January 25, 2001. Following an orientation session that described the NIOSH HHE program and provided basic information about 1-BP, employees were asked to sign a consent form signifying their agreement to participate in the HHE. The orientation and consent process for the employees of Marx Industries was conducted both in English and in Spanish. All questions regarding participation were answered prior to obtaining signed consent. Workers received instruction that they could choose to participate in all, some, or none of the HHE without penalty.

On Tuesday, Wednesday, and Thursday of the following week (January 30, January 31, and February 1, 2001) workers completed questionnaires. Spanish language questionnaires and a Spanish-speaking interpreter were available for any worker who requested them. The questionnaires included questions about current work activities and practices, length of employment at Marx Industries, previous and additional employment, and personal medical history information. The questionnaire included questions that dealt specifically with issues of reproductive and neurological health. Some of the questions regarding neurologic health dealt with the known acute narcotic (central nervous system depressant) effects of solvents. ${ }^{3}$

\section{Complete Blood Count}

Participants in the HHE had a blood sample collected both at the beginning of the work week and again at the end. One of the tests performed on the end-of-week blood was a CBC. This test measures several different components within the blood: total number of red blood cells (RBCs) and the amount of hemoglobin $(\mathrm{Hgb})$ inside them, total number of white blood cells (WBCs), and total number of platelets. Since blood cells are produced within the bone marrow, the $\mathrm{CBC}$ can be used as a measure of the health of the bone marrow, and has been used to evaluate other types of occupational exposures. ${ }^{4}$ Because bone marrow is known to be poisoned by some chemicals and there is evidence that bromopropanes may cause bone marrow damage, we collected a CBC to identify if 1-BP might be affecting the blood-forming system among Marx employees.

\section{Serum Chemistry}

The concentration of several different chemical components in the blood was measured for HHE participants. Serum chemistry levels measure the concentrations of sodium, potassium, chloride, carbon dioxide, blood urea nitrogen (BUN), and creatinine. Alterations in some or all of these values may serve as a marker for toxicity to the kidneys or other body organs.

\section{Serum, Whole Blood, and Urine Bromide Ion}

The concentration of $\mathrm{Br}$ in the serum (that portion of the whole blood after blood cells are removed) and in 
the urine was measured for workers at both the beginning and end of the work week. This test was performed to determine whether $\mathrm{Br}$ concentrations are elevated in the blood or urine of persons known to be exposed to 1-BP, and also to determine whether the measurement of $\mathrm{Br}$ concentrations in the serum or urine can be used as an accurate marker for exposure to 1-BP. At the end of the work week, a sample of whole blood was also collected to be tested for $\mathrm{Br}$ concentration. The whole blood $\mathrm{Br}$ concentration was also compared to other data to determine its suitability as a marker for exposure to 1-BP.

\section{Semen Samples}

Because 2-BP has been associated with effects on the male reproductive system, we collected semen samples from male Marx workers. Male volunteers who consented to provide specimens of semen for laboratory analysis were each given one insulated specimen container. Each participant also received both written and verbal instructions (in English or in Spanish) detailing how semen specimens were to be collected for optimal laboratory analysis. Participants were responsible for delivering specimens within 30 minutes of collection to an offsite laboratory during hours after work.

Semen samples were analyzed by NIOSH investigators at a local, off-site laboratory for (1) sperm count (the total number of sperm per cubic centimeter of semen) and (2) sperm motility (the percentage of sperm seen under a microscope to be moving normally). A portion of each semen sample was also sent to an outside contract laboratory for analysis of sperm morphology (shape). Normal ranges for each of these three measures (sperm count, motility, and shape) were used as comparative values. Based on these three measures, NIOSH investigators made a semi-quantitative assessment concerning whether each semen sample was normal or abnormal.

\section{Nerve Conduction Studies}

Because there is evidence that bromopropanes can cause neurological damage in laboratory animals, we performed nerve conduction testing in order to identify if 1-BP might be causing damage to the peripheral nervous system (i.e., those parts of the nervous system outside of the brain and spinal cord) of Marx workers. Nerve conduction testing is thought to be a sensitive indicator of damage to peripheral nerves (it may detect abnormalities in sensory nerves prior to the person being able to detect a sensory loss). ${ }^{5}$ On January 31,2001 , and February 1, 2001, participating Marx Industries' employees underwent nerve conduction studies. These studies were conducted by a contractor to NIOSH using a standardized method at an air temperature of at least 32 degrees Centigrade.

Nerve conduction tests are done by placing wires on the skin, giving a slight electrical stimulation, and measuring how fast electricity passes through specific nerves. These tests measure nerve conduction velocity and were performed in two nerves in the leg and one in the arm, by measuring the speed of the electrical impulse (in meters per second). The faster the nerve conduction velocity, the better. Nerve conduction tests also measure the number of nerve fibers stimulated by the impulse (called amplitude). The more nerve fibers stimulated, the better. There can be many causes of abnormal results in nerve conduction studies. Although this test can accurately measure delays in normal nerve conduction velocity, it cannot tell us why the nerve conduction velocity is slowed. In some situations, some amount of slowing may be normal while in other cases it may be pathological (a sign that something is wrong).

\section{Urinary Arsenic Levels}

As discussed above, occupational exposure to arsenic had been raised as concern in the HHE. At the end of the work week a sample of urine was collected and analyzed for the presence of inorganic arsenic and the two main metabolites of inorganic acid (monomethylarsonic acid and dimethylarsinic acid). For this HHE the total concentration of these three substances in urine is referred to as the total inorganic arsenic. Urine samples were collected in acid washed specimen cups and were shipped to the contract laboratory for analysis. Results were 
reported as micrograms of inorganic arsenic per gram of creatinine ( $\mu \mathrm{g} / \mathrm{g}$ creat).

\section{EVALUATION CRITERIA}

As a guide to the evaluation of the hazards posed by workplace exposures, NIOSH field staff employ environmental evaluation criteria for the assessment of a number of chemical and physical agents. These criteria are intended to suggest levels of exposure to which most workers may be exposed up to 10 hours per day, 40 hours per week for a working lifetime without experiencing adverse health effects. It is, however, important to note that not all workers will be protected from adverse health effects even though their exposures are maintained below these levels. A small percentage may experience adverse health effects because of individual susceptibility, a preexisting medical condition, and/or a hypersensitivity (allergy). In addition, some hazardous substances may act in combination with other workplace exposures, the general environment, or with medications or personal habits of the worker to produce health effects even if the occupational exposures are controlled at the level set by the criterion. These combined effects are often not considered in the evaluation criteria. Also, some substances are absorbed by direct contact with the skin and mucous membranes, and thus potentially increase the overall exposure. Finally, evaluation criteria may change over the years as new information on the toxic effects of an agent become available.

The primary sources of environmental evaluation criteria for the workplace are: (1) NIOSH Recommended Exposure Limits (RELs), ${ }^{6}$ (2) the American Conference of Governmental Industrial Hygienists' (ACGIH®) Threshold Limit Values (TLVs $\left.{ }^{\circledR}\right){ }^{7}$ and (3) the U.S. Department of Labor, OSHA Permissible Exposure Limits (PELs). ${ }^{8}$ Employers are encouraged to follow the NIOSH RELs, the ACGIH TLVs, or the OSHA limits, whichever is the more protective criterion.

OSHA requires an employer to furnish employees a place of employment that is free from recognized hazards that are causing or are likely to cause death or serious physical harm [Occupational Safety and Health Act of 1970, Public Law 91-596, sec. 5(a)(1)]. Employers should understand that not all hazardous chemicals have specific OSHA exposure limits such as PELs and short-term exposure limits (STELs). However, an employer is still required by OSHA to protect their employees from hazards, even in the absence of a specific OSHA PEL.

A time-weighted average (TWA) exposure refers to the average airborne concentration of a substance during a normal 8- to 10 -hour workday. Some substances have recommended STEL or ceiling values which are intended to supplement the TWA where there are recognized toxic effects from higher exposures over the short-term.

\section{1-BP and 2-BP Evaluation Criteria}

As with other solvents, occupational exposure to 1$\mathrm{BP}$ is thought to occur via both inhalation and skin absorption. Potential health effects related to overexposure to 1-BP (and many other solvents) may include irritation of the eyes, mucous membranes, upper respiratory tract, and skin. At higher levels of exposure, central nervous system depression (characterized by headache and dizziness, and possibly leading to loss of consciousness) may occur.

Animal studies and case studies of human exposure to 1-BP have suggested that excessive exposure may be associated with hematologic (blood forming), reproductive, and neurologic toxicity. ${ }^{9} \quad$ Several studies have attempted to evaluate the effects of 1-BP exposure on peripheral blood indices (blood cell counts). In those studies of chronic exposure to 1-BP in which blood cell counts and red blood cell parameters were measured, each employed a different exposure protocol, making comparability among the study results difficult. Results reported by different authors did not appear to be consistent at comparable levels of exposure. The major study of the effects of chronic inhalational exposure of 1-BP on the male organs of reproduction was conducted by Ichihara and colleagues. ${ }^{10}$ In this study, researchers 
divided male rats into 4 groups and exposed them to 1-BP at concentrations of $0,200,400$ or $800 \mathrm{ppm}$ for 8 hours a day for 12 weeks. The researchers identified several effects potentially related to 1-BP exposure. Although the results of the Ichihara paper are potentially of concern, it should be recognized that there is not always a direct correlation between specific targets in animal species when compared to humans. Since spermatogenesis and spermiation differ among species, the most sensitive sperm measures in one species may not be the same in another. This complicates extrapolating the results of this study to humans. Nonetheless, given the results of this paper, the following effects on the human organs of male reproduction might be expected to occur: (1) a decrease in the number of mature sperm or sperm with normal motility and/or morphology and (2) a decrease in semen volume as the seminal vesicles in exposed rats were found to be smaller in size than in controls (about $90 \%$ of semen volume comes from the seminal vesicles). Of interest, a different study showed that male rats exposed to concentrations of 1-BP at $1800 \mathrm{ppm}$ had increases in testicular weights as compared to control animals (contradicting the findings discussed earlier). ${ }^{11} \mathrm{~A}$ review of the literature relevant to neurotoxicity and occupational exposure to 1-BP and 2-BP is presented in Appendix 1.

Currently, there are no NIOSH, ACGIH, or OSHA exposure evaluation criteria for 1-BP. After a review of available exposure data and human and animal toxicologic data, but based primarily on data from animal studies (including effects on the male reproductive system [sperm motility]), a contractor for the EPA has proposed an Acceptable Industrial Exposure Limit (AEL) for 1-BP of $25 \mathrm{ppm}^{12}$ This AEL currently exists only in draft form and may be subject to further revision following public comment. Others have reviewed the literature and suggested that an occupational exposure limit of 60-90 ppm would be appropriate. ${ }^{9}$ The conclusions from this latter literature review were in part based on preliminary interpretation of data from a previous NIOSH HHE. ${ }^{13}$

Albemarle Corporation (a producer of 1-BP) has recommended an occupational exposure guideline for 1-BP, based on data from a two generation reproductive study in rats. ${ }^{14}$ In that study, young male and female rats received a daily 6-hour inhalation exposure to a known concentration of 1BP for a minimum of 70 days. After this period, the animals were paired for mating, and the daily exposures continued through the 14-day mating period, and through day 20 of gestation. No litters were observed in the 750 parts per million (ppm) exposure group, and a significant decrease was observed in the number and size of litters in the 500 ppm exposure group. A slight (insignificant) decrease was observed in the mean number of pups born and live pups per litter for the $250 \mathrm{ppm}$ exposure group. Based on these results and a 10-fold safety factor, Albemarle set their 1-BP recommended exposure guideline at $25 \mathrm{ppm}$ as an 8hour TWA exposure. ${ }^{15}$

The South Korea Ministry of Labor is the only government agency to develop an occupational exposure level (OEL) for 2-BP. In 1998, the Ministry issued a 2-BP OEL of $1 \mathrm{ppm}$ as an 8-hour TWA. ${ }^{16}$ This standard is based on a limited number of workplace epidemiological studies and toxicological (animal) studies which found that 2-BP exposure produces reproductive effects in both males (low sperm count) and females (ovarian dysfunction), and also affects the hematologic system. . $^{17,18,19,20,21,22}$

\section{Bromine}

Br-containing medications were widely used beginning in the late 1800 s until the 1940 s to prevent seizures and as sedatives. ${ }^{23} \mathrm{Br}$ toxicity, resulting from the chronic use (and abuse) of Br-containing drugs, was first recognized in the $1920 \mathrm{~s} .{ }^{24}$ Beginning in the late 1920s, reports in the medical literature described the signs and symptoms of Br toxicity, and the levels of $\mathrm{Br}$ in the blood necessary to produce them.

More recently, measurement of serum $\mathrm{Br}$ concentrations (the amount of $\mathrm{Br}$ dissolved in the blood) has been used to monitor for exposures to brominated compounds (for example, methyl bromide) in the workplace. ${ }^{25}$ In the case of 1-BP, it 
is known that the metabolism (breakdown by the body) of this chemical involves the debromination (removal of $\mathrm{Br}$ from) the parent molecule. ${ }^{26}$ Measuring $\mathrm{Br}$ levels among workers chronically exposed to 1-BP could serve as an indication of levels of exposure. ${ }^{27}$

$\mathrm{Br}$ is cleared from the body such that approximately half the body burden is excreted (passed in the urine) within about 12 days. For example, if, following an exposure, a person has a $\mathrm{Br}$ level measured in the blood at $10 \mathrm{mg} / \mathrm{dL}$, that level will fall to $5 \mathrm{mg} / \mathrm{dL}$ within about two weeks, provided there are no additional exposures. Treatment with intravenous fluids containing chloride will reduce the time required to excrete half the body burden of $\mathrm{Br}$ to approximately 3 days. ${ }^{23}$

Patients with chronic $\mathrm{Br}$ intoxication may present with a variety of signs and symptoms. ${ }^{24,28}$ In general, however, the earliest symptoms of $\mathrm{Br}$ toxicity are increasing agitation and irritability. ${ }^{23,24}$ Subsequent clinical signs of $\mathrm{Br}$ toxicity vary depending upon the concentration of $\mathrm{Br}$ in the body and the time course of intoxication. Patients who are early in the course of $\mathrm{Br}$ toxicity may complain of drowsiness, weakness, confusion, agitation, slurring of speech, loss of interest in normal activities, decreased memory, and a decreased appetite. ${ }^{23,24,28}$ As the intoxication becomes more chronic and as $\mathrm{Br}$ levels increase, patients may have more slurring of speech and increasing difficulty with their ability to speak clearly (dysarthria). ${ }^{23,28,29}$ Persons with severe $\mathrm{Br}$ intoxication may ultimately develop a psychosis similar to schizophrenia, seizures, and stupor, delirium or coma. ${ }^{23,24,28,29}$ Apart from the signs mentioned above, neurological findings may vary from patient to patient without a consistent pattern of dysfunction. ${ }^{23}$ Abnormalities with gait, reflexes, and the eye examination have been reported. Skin rash, described as one of the classic findings of $\mathrm{Br}$ toxicity, occurs in $25-30 \%$ of cases of $\mathrm{Br}$ intoxication. ${ }^{23,28}$ This rash, which is described as "acneiform" (similar to acne in appearance) may appear on the face, trunk, or legs. ${ }^{23,24,28}$ However, high levels of $\mathrm{Br}$ have been observed in the absence of any rash. ${ }^{28}$
In the general, unexposed population, $\mathrm{Br}$ levels (in whole blood and in serum) range from $0.35 \mathrm{mg} / \mathrm{dL}$ to $0.49 \mathrm{mg} / \mathrm{dL}$ and typically do not exceed 0.5 $\mathrm{mg} / \mathrm{dL}^{24,28}$ Reports in the medical literature reveal that the therapeutic range of $\mathrm{Br}$ concentrations in patients prescribed Br-containing medications is from $48-96 \mathrm{mg} / \mathrm{dL}{ }^{24}$ Although cases of Br toxicity have been reported at blood levels as low as 4 $\mathrm{mg} / \mathrm{dL},{ }^{25}$ this is distinctly unusual. More typically, levels less than $40-50 \mathrm{mg} / \mathrm{dL}$ are considered to be relatively safe, ${ }^{23,28}$ and even levels less than $80 \mathrm{mg} / \mathrm{dL}$ may not manifest obvious clinical effects. ${ }^{24}$ There is not, however, uniform agreement as to the levels at which clinical symptoms become apparent. Based on a review of the literature, correlations between $\mathrm{Br}$ levels in the blood and expected symptoms cannot be readily made. Potentially fatal blood $\mathrm{Br}$ levels range from $200 \mathrm{mg} / \mathrm{dL}$ to $300 \mathrm{mg} / \mathrm{dL}$ and above. ${ }^{24,25,29}$

\section{Urinary Arsenic}

Arsenic is an element which is found naturally in low levels in our environment, but which is a poison when too much is taken up in the body. Arsenic has many uses in industry. When it is used in industry, arsenic is most often in its inorganic form. Low levels of inorganic arsenic, occurring naturally, can also be found in well water in many places in the United States and around the world. If a person has an increased level of inorganic arsenic in their body, it is likely that that person is being exposed to arsenic from some source-possible routes of exposure could include ingestion (food, water, contaminants from some other source) and inhalation (airborne). Although the concentration of inorganic arsenic in the urine of persons not exposed to arsenic in the workplace is variable, ${ }^{30}$ persons who have no unusual exposures to arsenic frequently have levels of inorganic arsenic in the urine of less than approximately $20-25 \mu \mathrm{g} / \mathrm{L} .{ }^{31}$ For this HHE, we are considering an elevated level of inorganic arsenic in the urine to be $25 \mu \mathrm{g} / \mathrm{g}$ creat or more, indicating possible environmental or occupational exposure to arsenic $(\mu \mathrm{g} / \mathrm{g}$ creat of a substance in urine is often similar to $\mu \mathrm{g} / \mathrm{L}$ of urine $[1 \mathrm{~L}$ urine often contains approximately $1 \mathrm{~g}$ creat]). The ACGIH recommends a biological exposure index (BEI) for arsenic (as inorganic arsenic) in urine of $35 \mu \mathrm{g} / \mathrm{L}^{7}$ 
RESULTS

\section{November 1999: Initial 1-BP and 2-BP Exposure Assessment and Medical Evaluation}

A total of 17 workers participated in the air monitoring. One of these workers left work early, allowing us to gather full-shift exposure data only for the remaining 16 workers. Of these workers, seven were Glue Line sprayers, and five were Springs Line sprayers. In addition, there was a doffer and supervisor/set-up person from both the Glue and Spring Lines.

The data from the complete 1-BP and 2-BP inhalation exposure determinations are located in Table 1, and summary results based on the 16 full-shift 1-BP exposure measurements are in Table 2. The geometric mean (GM) 1-BP exposure for all 16 full-shift exposure measurements was $81.2 \mathrm{ppm}$ (range: 18.1 to $253.9 \mathrm{ppm}$ ). The GM 1-BP concentrations for workers on the Springs Line (98.6 $\mathrm{ppm})$ and on the Glue Line (69.8 ppm) were significantlly different $(p=0.4)$. The GM 1-BP concentration for sprayers on the Springs Line (139.1 ppm) and on the Glue Line (88.4 ppm) were also significantlly different $(\mathrm{p}=0.1)$. The GM 1-BP exposure for all sprayers was $107.6 \mathrm{ppm}$ (range 57.7 to $253.9 \mathrm{ppm}$ ).

Summary data based on the 16 full-shift 2-BP inhalation exposure measurements are in Table 3. The GM 2-BP exposure was $0.24 \mathrm{ppm}$, and the exposures ranged from 0.08 to $0.68 \mathrm{ppm}$. The GM 2-BP concentration for workers on the Springs Line was $0.28 \mathrm{ppm}$; that of workers on the Glue Line was $0.22 \mathrm{ppm}$. The GM 2-BP concentration for sprayers on the Springs Line was $0.38 \mathrm{ppm}$; that of sprayers on the Glue Line was $0.26 \mathrm{ppm}$.

Two area air samples were collected in areas adjacent to the Glue and Springs Lines. The purpose of these air samples was to determine if 1-BP and 2-BP vapors were migrating to other areas. The airborne 1-BP and 2-BP concentrations measured in the sample from the Focus Saw Area near the Springs Line were $8.7 \mathrm{ppm}$ and $0.06 \mathrm{ppm}$, respectively. The airborne 1-BP concentration measured in the sample from the cutting area adjacent to the Glue Line was $5.3 \mathrm{ppm}$. Unfortunately, 2-BP could not be determined in this second sample due to the presence of an unknown interference (not present in other samples).

A review of the company's OSHA 200 Logs for 1997, 1998, and 1999 revealed that recordable illnesses due to adhesive exposure were confined to 1999. Ten employees were listed as having illnesses reported to be due to adhesive exposure. In addition to the 10 listed employees, NIOSH investigators learned that an additional 11 employees had also undergone blood testing to evaluate for the presence of elevated serum Br levels. The results of that testing was not available for review. Following review of the OSHA logs, the NIOSH medical officer held confidential interviews with 4 of the 10 employees who were listed as having illnesses reported to be due to adhesive exposure, 2 of whom were among the 4 index cases. At the time of the interviews, 2 of the 4 persons noted persistent headaches. All four employees described a numbness or a "pins and needles" sensation in both legs and feet. The employees reported that this sensation had been present for a variable length of time, but all reported that it was slowly improving.

\section{January 2001: Second 1-BP and 2-BP Exposure Assessment}

Table 4 shows the bromopropane exposures of the Marx workers considered unexposed to 1-BP (personnel not working near the adhesive spray lines), while exposures for exposed workers (personnel working near the spray adhesive lines) are listed in Table 5. Summary statistics for the data in these two tables are presented in Tables 6 and 7. The GM 1-BP exposure for unexposed workers was 1.1 ppm (range: $0.1-4.9$ ppm). All 2-BP exposures for 
unexposed workers were below the MQC of 0.01 ppm. The GM 1-BP exposure for exposed workers was $45.8 \mathrm{ppm}$ (range: $7.2-280.5 \mathrm{ppm}$ ), significantly greater than the 1-BP exposure among unexposed workers $(p<0.01)$. The GM 2-BP exposure for exposed personnel was 0.07 ppm (range: ND [nondetectable]-0.52 ppm). As during the initial exposure monitoring survey in November, Springs Line sprayers had higher full-shift 1-BP exposure $(\mathrm{GM}=162.2 \mathrm{ppm})$ than did the Glue line sprayers $(\mathrm{GM}=58 \mathrm{ppm})$, although the difference was not statistically significant $(p=0.2)$. Two sprayers rotated between the Springs Line and the Glue Line during the day. The GM exposure for 1-BP of these two sprayers was $116 \mathrm{ppm}$.

\section{January 2001: Medical Survey}

Forty-three (72\% of the 60 workers) persons participated in the questionnaire survey. Among those, 41 provided job title information, including the following: 7 saw operators, 4 hand cutters, 1 baler operator, 5 sprayers on the Springs Line (also called gluers) and 5 sprayers on the Glue Line, 4 sewers, 3 fiber handlers, and 12 in the category of 'other' (which included a variety of job tasks including supervisors). All the sprayers except one were considered to be exposed to 1-BP during their usual job tasks based on observation of their work practices (one person had a job title of sprayer but actually did not perform spraying activities). Four other persons, including one saw operator and three listed as 'other,' were also considered to be exposed to 1-BP based on job tasks. Therefore, there were a total of 13 persons considered exposed to $1-\mathrm{BP}$ based on knowledge of job tasks. A description of survey participants is provided in Table 8. Among the total respondents there were 24 females and 18 males (one participant did not provide demographic information). The mean age was 34 years and the median time working at Marx Industries was 29 months. As presented in Table 8, workers considered to be exposed to 1-BP had a significantly higher mean exposure (GM 46 ppm [range 7 ppm $281 \mathrm{ppm}]$ ) as measured by January $2001 \mathrm{PBZ}$ air sampling compared to workers unexposed (GM 1.1 ppm [range 0.1 - 5 ppm]). Workers exposed to 1-BP were more likely to be female, younger, and
Hispanic. Current cigarette smoking was similar among the two groups. Among all respondents, only one said they wore gloves when handling foam cushions, one said they wore a respirator at work, and three said they wore protective clothing at work.

\section{Serum, Urine, and Whole Blood $\mathrm{Br}$}

Appendix 2 contains all data for the serum, urine, and whole blood $\mathrm{Br}$ testing. Table 9 provides summary data for these analyses by exposure status. Forty-two participants had start-of-week serum $\mathrm{Br}$ concentrations tested and thirty-nine had end-ofweek serum $\mathrm{Br}$ concentrations tested; thirty-nine completed both tests. The GM serum $\mathrm{Br}$ concentration for the end-of-week testing was 4.8 $\mathrm{mg}$ / (range 1.7 to 43.5 ). The average difference between the end-of-week and the start-of-week serum $\mathrm{Br}$ concentrations was $1.0 \mathrm{mg} / \mathrm{dl}$; this varied between the exposed $(2.3 \mathrm{mg} / \mathrm{dl}$, range -3.2 to 7.5$)$ and the unexposed $(0.3 \mathrm{mg} / \mathrm{dl}$, range -0.9 to 1.9$)$. Overall, 12 of the 39 (three among exposed workers, and 9 among unexposed workers) cross-week differences were negative numbers; a cross-week difference less than zero indicates a drop in serum $\mathrm{Br}$ concentration during the week.

Forty-two participants had start-of-week urine $\mathrm{Br}$ concentrations tested and 40 had end-of-week urine Br concentrations tested; 40 completed both tests. The GM Br concentration for the end-of-week testing was $46.5 \mathrm{mg} / \mathrm{dl}$ (range 15.4 to 595.4). The average cross-week difference in urine $\mathrm{Br}$ concentrations was $41.9 \mathrm{mg} / \mathrm{dl}$; this varied between the exposed (131.1 mg/dl, range -20.1 to 496.6) and the unexposed $(3.6 \mathrm{mg} / \mathrm{dl}$, range -29.5 to 77.2$)$. Overall 13 of the 40 (two among exposed workers, and 11 among unexposed workers) differences were negative numbers; a cross-week difference less than zero indicates a drop in urine Br concentration during the week.

Forty participants had whole blood Br concentrations tested. The GM whole blood $\mathrm{Br}$ concentration was $4.7 \mathrm{mg} / \mathrm{dl}$ (range 1.9 - 32.6). 
All measures of exposure $(\mathrm{Br}$ in serum, urine, and whole blood) were statistically significantly greater among the exposed group compared to the unexposed group. Additionally, all five measures of exposure (end-of-week and start-of-week serum and urine $\mathrm{Br}$, and whole blood $\mathrm{Br}$ ) were correlated with individual PBZ 1- BP air concentrations (Table 10); all the correlations (coefficients ranged from 0.37 to 0.88 ) were statistically significant. The relationships with the highest correlation coefficient $(\mathrm{r}=0.88)$ were between 1-BP air concentration and end-of-week serum and whole blood $\mathrm{Br}$ concentrations. The cross-week differences of both serum and urine $\mathrm{Br}$ concentrations were also correlated with the air measure (although the correlation coefficients were lower).

\section{Questionnaires-Questions Concerning Possible Excessive Exposure to Solvent}

One of the purposes of the questionnaire was to assess the prevalence of symptoms (occurring in the 30 days prior to the survey) that could be consistent with excessive exposure to brominated solvents. Included among these were questions concerning anxiety (nervousness), feeling drunk, headache, trouble concentrating, unusual fatigue (sleepiness), paresthesias (numbness and tingling) in hands or feet, and tremor. Among these symptoms, headache was the symptom reported by the most workers ( 22 workers). The prevalence of these seven symptoms among the 13 exposed workers (compared to the unexposed workers) is reported in Table 11. Anxiety (nervousness) was the only symptom reported significantly more frequently among the exposed workers compared to those unexposed.

Analyses of PBZ 1-BP exposure among employees by presence or absence of these symptoms are reported in Table 12. Employees reporting anxiety (nervousness), headache, and feeling drunk had statistically significantly higher PBZ concentrations of 1-BP compared to those not reporting those symptoms.

\section{Complete Blood Count}

Of the 43 participants in the questionnaire survey, 3 responded that they had a doctor-diagnosed history of anemia; all 3 were among the unexposed group. Forty workers had blood samples analyzed for a CBC. All of the measures of RBC, hemoglobin, and platelets were within the normal ranges provided by the laboratory. One person (unexposed to 1-BP), had a WBC count of 3,700 cells per cubic millimeter $\left(\mathrm{mm}^{3}\right)$, slightly below the lower end of the normal range for WBC (normal range: 3,900 - 11,400 cells $/ \mathrm{mm}^{3}$ ). The remainder of the WBC measures were within the normal range. Table 13 presents the median values for the $\mathrm{CBC}$ parameters; there were no statistically significant differences in the medians of these parameters between the exposed and unexposed workers. Complete $\mathrm{CBC}$ data is presented with exposure information in Appendix 2.

Linear regression was performed to evaluate possible sub-clinical effects of exposure to 1-BP on the peripheral blood indices (which were all within laboratory normal ranges [one exception noted above]). Exposure was assessed by both PBZ 1-BP concentrations and by end-of-week urine $\mathrm{Br}$ concentration. We found no statistically significant relationships between exposure (increasing 1-BP $\mathrm{PBZ}$ air or urine $\mathrm{Br}$ concentrations) and individual cell counts or hemoglobin concentration (Table 14).

\section{Serum Chemistry}

Concentrations of sodium, potassium, chloride, carbon dioxide, BUN, and creatinine for the participants were compared to the normal ranges for clinical specimens provided by the laboratory. The concentrations of all these substances in the serum were within, or close to, the normal ranges. There was no pattern of abnormality suggesting any workrelated affect on the concentrations of these substances.

\section{Reproductive Issues}

\section{Questionnaire}


Of the 42 persons who completed the reproductive questions on the questionnaire, none responded that they had a doctor-diagnosed reproductive or infertility problem. The 18 men participating in our survey represented $67 \%$ of the 27 men employed at Marx Industries at the time of this HHE; 17 of the men provided answers to questions pertaining to male reproductive history. Of the 17 respondents, one answered that he had tried but failed to father a child, and a different worker responded that he had difficulty with having or maintaining an erection. The first of these workers was considered unexposed to 1-BP (by evaluation of job duties), had low measures of exposure to 1-BP (PBZ 1-BP air and urine $\mathrm{Br}$ concentrations), and did not take part in the male reproductive evaluation. The second worker was considered exposed to 1-BP based on evaluation of job duties, although his PBZ air concentration of 1-BP was similar to those levels found among the unexposed group. Semen analysis of this worker fell within or close to the normal range and he was determined by NIOSH investigators not to have any evidence at the time of the survey of damage to the sperm-forming system. No other respondents reported difficulties in having or maintaining an erection. No respondents reported a history of miscarriage or wives/partners with difficulty becoming pregnant in the year prior to the NIOSH survey.

Twenty-four $(73 \%)$ of the thirty-three women employed at Marx Industries at the time of this HHE completed the health survey questionnaire. Not all women answered all questions concerning reproductive health; the questionnaire included some questions that were not applicable to all participants. There was no increase in reports of abnormal menstruation (unusual menstrual cycle or heavy bleeding), inability to become pregnant, or miscarriage among women exposed to 1-BP compared to women not exposed.

\section{Semen Samples}

Nine $(50 \%$ of the 18 male participants) men participated in the laboratory evaluation of male reproductive function. Three of the nine participants were among the thirteen exposed workers (the other ten exposed workers were female). The PBZ air concentrations of 1-BP for the three men were 10.4, 18.8 , and $79.5 \mathrm{ppm}$. Equipment difficulty in the field during the survey delayed analyses for sperm motility. Because of potential effects of lowered temperature on sperm motility, these types of evaluations are usually performed within 90 minutes of collection. In this HHE, some of the analyses were not performed until almost 120 minutes after collection. However, percent motility of sperm in the semen samples and sample age were not correlated, suggesting that adverse effects of increased time prior to analysis on sperm motility were not observed with these samples.

After reviewing all three components of the semen analyses for the nine men, the NIOSH investigators determined that five of the nine men had an abnormal semen analysis. Four of these five with abnormal semen analyses were unexposed to 1-BP and one was exposed (Table 15). In particular, two participants had notable abnormalities in the sperm heads. The first of these two persons had two types of unusual sperm shapes-this person was unexposed to 1-BP and had 1-BP exposure measures (1-BP PBZ air concentration and end-of-week urine $\mathrm{Br}$ concentration) close to the GM for the unexposed group. The second of the two had one type of unusual sperm shape - this person was exposed to 1$\mathrm{BP}$ and had a PBZ air concentration of $10.5 \mathrm{ppm}$ (less than the GM of air concentrations among the exposed) and an end-of-week urine Br concentration of $109.8 \mathrm{mg} / \mathrm{dL}$ (less than the $\mathrm{GM}$ urine $\mathrm{Br}$ concentrations among the exposed).

Analyses to evaluate relationships between measures of exposure (including 1-BP PBZ air concentration and end-of-week urine $\mathrm{Br}$ concentration) and the three sperm indices revealed no evidence of statistically significant correlation (Table 16).

\section{Nerve Conduction Studies}

Forty-two (98\%) of the forty-three participants had nerve conduction studies performed. The one worker who did not have nerve conduction testing done was unexposed. Of the 42, $29(69 \%)$ studies were complete and judged by the consulting 
physician to be normal, $4(10 \%)$ were incomplete tests but without an identifiable abnormality, and 4 $(10 \%)$ were complete, not abnormal, but considered to be borderline by the consulting neurologist. Thus, 37 ( $88 \%$ of the 42$)$ tests were classified as normal or borderline. Four tests were determined by the consulting physician to be abnormal and one was 'probably abnormal;' these five ( $12 \%$ of the 42 ) were classified as abnormal. Among the five workers with abnormal tests, two were among the thirteen workers exposed to 1-BP, although neither were sprayers. This yielded a PR for an abnormal nerve conduction test among exposed workers of 1.5 , with a $95 \%$ $\mathrm{CI}=0.3$ - 7.9. $\mathrm{PBZ}$ exposure to 1-BP or end-of-week urine $\mathrm{Br}$ concentration were higher among persons with normal nerve conduction testing although the differences were not statistically significant (Table 17).

To determine if there might be some effect not apparent due to the borderline nature of four of the tests, the four borderline nerve conduction tests were alternatively grouped with the abnormal tests (so that there were a total of 9 abnormal tests and 33 normal tests). Among the nine workers with abnormal tests by this alternate grouping, two were exposed to 1-BP and seven were unexposed (all four of the persons with borderline tests were unexposed). The same analyses as those done above were done with this alternate grouping; the results were consistent with those presented above.

\section{Urinary Arsenic Concentrations}

Forty-one participants provided urine specimens that were analyzed for total inorganic arsenic. Twelve workers had levels of inorganic arsenic above 25 $\mu \mathrm{g} / \mathrm{g}$ creat; ten $(83 \%)$ of those twelve workers had jobs near or on the Springs and Glue Lines. In personal letters sent to all participants, it was recommended to all 12 that they follow up with their physicians concerning the finding of arsenic in their urine. Eight of these workers had levels that were above $35 \mu \mathrm{g} / \mathrm{g}$ creat; levels of inorganic arsenic above $35 \mu \mathrm{g} /$ liter are above the ACGIH BEI. As a result, NIOSH investigators conducted a thorough examination of the Marx workplace for a source of arsenic, the results of which are summarized below.

\section{May 2001: Arsenic Investigation}

No arsenic was detected in any of the 18 air or 17 bulk samples collected during the May 2001 environmental evaluation. The minimum detectable concentration for airborne arsenic was $0.6 \mu \mathrm{g} / \mathrm{m}^{3}$, well below both the ACGIH TLV and the OSHA PEL of $10 \mu \mathrm{g} / \mathrm{m}^{3}$. The drinking water samples also did not have detectable levels of arsenic; the analytical limit of detection for the method used for drinking water analysis was $2 \mu \mathrm{g} / \mathrm{L}$, well below the legal limit of $10 \mu \mathrm{g} / \mathrm{L}$ ( 10 parts per billion of arsenic in drinking water). ${ }^{32}$ One of the 30 surface wipe samples, collected on the concrete surface of the loading dock, had a detectable quantity of arsenic on it. This indicated that a very small amount of arsenic was present on the Marx Industries property, but was not likely to account for the elevated urinary arsenic levels found among employees. During the site visit, NIOSH investigators looked for other possible common sources of arsenic exposure among employees. No epidemiological links other than assigned work tasks (for example, persons with both high and low urinary arsenic levels socialized and took breaks and ate lunch together) were found.

\section{DISCUSSION AND CONCLUSIONS}

\section{1-BP Industrial Hygiene Exposure Assessment}

During the initial exposure assessment (November 1999), the 1-BP exposure data indicated that 15 of 16 foam fabrication line personnel had inhalation exposures in excess of the $25 \mathrm{ppm}$ exposure criteria recommended in draft form by the US EPA and by the Albermarle Corporation. Seven workers had 1-BP exposures exceeding $100 \mathrm{ppm}$; all seven were sprayers (three from the Glue Line and four from the Springs Line). Area air sampling identified low concentrations of 1-BP in areas adjacent to the foam fabrication lines, indicating that 1-BP vapors were 
migrating from the spraying operations. None of the 2-BP exposure measurements from the November 1999 survey exceeded the exposure guideline of 1 ppm. Based on these data, in the February 2000 interim letter, NIOSH representatives recommended to Marx that efforts be made to reduce exposure of spray line personnel to 1-BP. NIOSH investigators were not aware of any substantial changes in engineering or administrative controls, or in the employee use of personal protective equipment, to reduce exposure to 1-BP at Marx during the time interval between the November 1999 and January 2001 surveys.

During the January 2001 exposure assessment, we found that overall 1-BP exposures among employees on or near a foam fabrication line decreased, although the decrease was not statistically significant (45.7 ppm [GM] versus $81.2 \mathrm{ppm}$ [GM]; $\mathrm{p}=0.14$ ). This observed decrease was primarily among the sprayers on the Glue Line; the 1-BP exposure among the sprayers on the Springs Line was similar in the two surveys. In the January 2001 survey, exposed workers had greater exposure to 1-BP than did unexposed workers. Eight of thirteen foam fabrication line personnel had 1-BP exposures in excess of 25 ppm; all were sprayers (range: 38 - 281 $\mathrm{ppm})$. Four of the eight sprayers had 1-BP exposures exceeding $100 \mathrm{ppm}$. The exposed employees also had the highest serum $\mathrm{Br}$ levels (range $=2.7$ - 43.5 $\mathrm{mg} / \mathrm{dL}$, end-of-week serum bromide levels). Among the unexposed workers, none had 1-BP exposures exceeding 5 ppm (range: 0.1 - $4.9 \mathrm{ppm}$ ). Although levels of measured exposure were low, the data from the unexposed workers, as well as the area sampling in the areas away from the foam fabrication lines, indicate that 1-BP vapor migrates into non-spraying areas of the plant. Regarding 2-BP, none of the workers considered to be exposed to 1-BP had 2-BP exposures above $1 \mathrm{ppm}$; only trace amounts of 2-BP were found in non-spraying areas of the plant.

Considering the above findings, the NIOSH investigators believe there is convincing evidence that the foam fabrication line exhaust fans are not adequately capturing the 1-BP vapors generated during the spray adhesive operations. Most workers on the two foam fabrication lines are exposed to 1-
$\mathrm{BP}$ at concentrations above $25 \mathrm{ppm}$, and some are exposed to much higher concentrations. Additionally, 1-BP vapors are migrating (albeit at low levels) to nearby areas.

Whenever there is a potential for a hazardous exposure in a workplace, traditional industrial hygiene practice dictates that the following hierarchy of controls, in decreasing order of desirability and effectiveness, be implemented to protect worker health:

1. Elimination of the toxic substance from the workplace.

2. Substitution of the toxic substance with a less toxic substance.

3. Installation of engineering controls designed to reduce exposure.

4. Use of administrative controls to reduce exposure.

5. Use of personal protective equipment to reduce exposure.

In many instances, it is not possible to eliminate or substitute a chemical or material from a production process without altering the integrity of the desired product. Thus, many strategies for reducing hazardous exposures center on the use of engineering controls such as process isolation and/or local exhaust ventilation. The NIOSH investigators believe the 1-BP vapors can be controlled using a spray booth at each work station, with each booth containing a local exhaust ventilation system that discharges the captured air and vapors outside the building. In two other facilities that use spray adhesives where NIOSH has conducted HHEs, the combination of partial enclosure and local exhaust ventilation has been highly successful in lowering sprayer exposures to 1-BP and 2-BP. ${ }^{13,33}$ PPE is frequently used to protect workers from hazardous exposures. PPE should only be used when engineering controls are not feasible, in the interim when engineering controls are being installed or repaired, or when engineering controls have not sufficiently reduced exposures.

Regarding 2-BP, NIOSH investigators believe it is prudent to use a spray adhesive formulation with the lowest concentration of 2-BP. 


\section{1-BP Medical Survey}

\section{Markers of Exposure to 1-BP}

Our survey demonstrated that airborne 1-BP concentrations were correlated with start-of-week and end-of-week urine and serum $\mathrm{Br}$ concentrations, as well as with end-of-week whole blood $\mathrm{Br}$ concentration. Based on the fact that previous studies have used urine $\mathrm{Br}$ as a marker of exposure, ${ }^{34}$ we chose to use end-of-week urine $\mathrm{Br}$ as a marker of exposure for some of the analyses in this report. Both the urine and the serum testing cross-week difference (end-of-week minus start-of-week) yielded negative results for some participants (both exposed and unexposed), indicating a decrease in $\mathrm{Br}$ concentration during the week. There are several possible explanations for the decreasing $\mathrm{Br}$ concentration at the end of the week that we observed among exposed workers. It may be that exposure to 1-BP in the time period prior to our survey was greater than that during our survey, leading to declining $\mathrm{Br}$ levels (reflecting the decreased exposure); alternatively, it may be that random variation among individuals' $\mathrm{Br}$ levels are reflected in our testing. Other aspects of 1-BP metabolism which were not evaluated may also be important. We conclude that serum, urine, and whole blood $\mathrm{Br}$ concentrations may all be good indicators of 1-BP exposure. There is evidence that 1-BP excreted unchanged in the urine may be, in some instances, a more suitable choice of a biomarker. $^{34}$ However, urinary 1-BP detection requires gas chromatography-mass spectrometry (GC-MS) instrumentation and the specimen must be analyzed immediately after collection. The financial and logistical costs of this test may make its performance difficult to implement on a widespread basis. Conversely, most clinical laboratories can perform analysis for $\mathrm{Br}$, and analysis may be delayed without serious degradation of specimen quality. Therefore, cost constraints would be a main reason why $\mathrm{Br}$ analysis might be chosen over 1-BP anlaysis by GC-MS analysis as a marker of 1-BP exposure. Further research is needed to learn more about the most appropriate use of biologic markers of exposure to $1-\mathrm{BP}$.

\section{Bromism and Questionnaire Assessment of Solvent-Related Symptoms}

Of the four Marx workers who had been hospitalized prior to the HHE, one had a serum $\mathrm{Br}$ level (measured during hospitalization) of $24 \mathrm{mg} / \mathrm{dL}$; the remaining three had serum $\mathrm{Br}$ levels in excess of 50 $\mathrm{mg} / \mathrm{dL}(77 \mathrm{mg} / \mathrm{dL} ; 53 \mathrm{mg} / \mathrm{dL} ; 100 \mathrm{mg} / \mathrm{dL})$. It should be noted that one of the four (serum $\mathrm{Br}=77 \mathrm{mg} / \mathrm{dL}$ ) did not have this level checked until the third hospital day (and after receiving intravenous fluids), and therefore could have had substantially higher levels on admission to hospital. Among current Marx workers at the time of the NIOSH survey, the highest measured serum $\mathrm{Br}$ level was $43.5 \mathrm{mg} / \mathrm{dL}$.

A review of the medical literature (see Evaluation Criteria) indicates that serum $\mathrm{Br}$ levels in excess of $0.5 \mathrm{mg} / \mathrm{dL}$ are considered elevated. Br levels of less than $40-50 \mathrm{mg} / \mathrm{dL}$ in the serum are generally not associated with toxicity, although the range of serum $\mathrm{Br}$ levels associated with symptoms has been reported to vary widely. Analysis of symptom information collected from the questionnaires reveals that exposure to 1-BP was associated with symptoms that could potentially be due to early bromide toxicity (including feeling drunk or anxious [nervous]) and/or symptoms that could be due to general solvent toxicity (including headache). It must be noted that all the symptoms used in our questionnaire to assess possible acute solvent-related health effects are nonspecific symptoms which could have many potential causes.

Separately, the four workers who had been hospitalized all described both problems walking and painful tingling/numbness/pins and needles feeling in the feet as among their most prominent symptoms. While problems walking (ataxia) has been identified in the literature as occurring as a result of bromide toxicity, painful tingling/numbness/pins and needles feeling (paresthesias) have not. 
Our findings suggest that excessive exposure to 1-BP may be related to some acute symptoms that have been associated with excessive exposure to $\mathrm{Br}$. However, the limitations of our HHE (described below) and the fact that we did not see a consistent association of 1-BP exposure with similar symptoms (e.g., differing results for feeling drunk and trouble concentrating) indicate that further work is needed to confirm these findings.

\section{CBC}

Our CBC testing found no clinically relevant abnormalities in the cell or platelet counts, and we found no differences in the hemoglobin concentrations and cell or platelet counts between the exposed and unexposed workers. Our statistical analyses of the individual cell and platelet counts and hemoglobin concentrations by exposure to 1-BP revealed no statistically significant correlations within the normal ranges of the $\mathrm{CBC}$ indices.

\section{Reproductive Issues}

Nine male workers took part in the semen analysis portion of the medical survey, and of those nine, only three were among the exposed workers. Among this small number of participants, we found no evidence of decreases in sperm number, shape, or motility related to 1-BP exposure.

\section{Nerve Conduction Tests}

We conducted nerve conduction testing on 42 of the $43 \mathrm{HHE}$ participants, and identified five persons with abnormal nerve conduction tests; however, we found no relationship between abnormal nerve conduction and 1-BP exposure.

\section{Survey Limitations}

The ability of this survey to detect potential associations between 1-BP exposure and health effects was limited by several factors. The first limitation was the small number of participants in each group, which decreases our ability to detect differences between the exposed and unexposed groups. A second limitation was the moderate participation rate (72\%) for our HHE; because not all the Marx workers participated, our findings may be subject to selection bias (persons who participated may not be representative of all the workers). A third limitation involves the possibility that some workers may be more likely than others to have health effects related to occupational exposure to 1$\mathrm{BP}$, and the possibility that those workers may have removed themselves from the workplace (due to those health effects) prior to our HHE. Of the ten employees (including the four workers treated at the hospital) identified in the November 1999 OSHA $200 \log$ review as having illnesses reported to be due to adhesive exposure, only one was still working at Marx Industries at the time of the medical survey in January 2001; that employee did not fully participate in the survey. And lastly, as mentioned in Results, a limitation in the reproductive portion of the HHE involved delays in analyzing sperm motility. Although we did not see an obvious effect of this delay, an effect cannot be ruled out.

\section{Arsenic}

Arsenic intoxication represents another potential explanation for the findings of ataxia and paresthesias among the four Marx workers hospitalized prior to the HHE (ataxia and paresthesias in the legs can occur 5 to 10 days following large acute arsenic intoxication and also after chronic but more moderate arsenic exposures). All four workers had total (organic and inorganic) urinary arsenic levels of at least $200 \mu \mathrm{g} / \mathrm{L}(224 \mu \mathrm{g} / \mathrm{L} ; 200 \mu \mathrm{g} / \mathrm{L} ; 318 \mu \mathrm{g} / \mathrm{L} ; 224$ $\mu \mathrm{g} / \mathrm{L})$ measured either during or shortly after their hospital stays in March 1999. The percentages of organic (non-toxic) and inorganic (toxic) arsenic in the samples collected from these 4 individuals is unknown. In this HHE (nearly two years after the workers were hospitalized), NIOSH investigators collected spot urine samples from 41 employees at Marx Industries and analyzed for the presence of inorganic (toxic) arsenic separately from that of organic (non-toxic) arsenic. Inorganic arsenic levels in these samples ranged from $6-215 \mu \mathrm{g} / \mathrm{g}$ creatinine $(5-271 \mu \mathrm{g} / \mathrm{L})$. 
Previous research has shown that levels of urinary arsenic of approximately $35 \mu \mathrm{g} / \mathrm{L}$ typically occur when airborne concentrations are on the order of 10 $\mu \mathrm{g} / \mathrm{m}^{3}{ }^{35}$ Such concentrations of arsenic in air were not found during either the NCDOL investigation of April 1999 or during the thorough investigation undertaken as part of this HHE. No arsenic was found in bulk samples of materials from Marx, and only a trace amount of arsenic was found in one of 30 wipe samples. NIOSH investigators concluded from these data that the elevated urinary inorganic arsenic concentrations of Marx workers which we found as part of our HHE were not due to workplace exposures at Marx. Individual follow-up of employees with their personal physicians is indicated to determine the clinical significance, and potentially the source of, these elevated urine arsenic concentrations. Regarding the four workers treated at the hospital prior to the HHE, review of medical records (including electrophysiological testing [nerve conduction studies and electromyography]) revealed that none of the four had a history of or displayed other physical or laboratory findings consistent with a diagnosis of acute or chronic arsenic toxicity; ${ }^{* *}$ therefore, NIOSH investigators do not believe that arsenic intoxication (as reflected by elevated total urinary arsenic levels alone) sufficiently explains the presence of ataxia and paresthesias among those four workers.

\section{RECOMMENDATIONS}

There are very few published data on human health effects associated with 1-BP exposure, and a limited amount of toxicologic data from studies in animals (see Appendix 1). The exposure criteria of $25 \mathrm{ppm}$

\footnotetext{
** Signs and symptoms of acute arsenic intoxication include gastrointestinal upset (nausea, vomiting, diarrhea, abdominal pain); findings of kidney, liver, and heart damage; a brown peeling rash on palms and soles; appearance of Mee's lines on the nails; bone marrow damage; and unusual appearance of red blood cells under a microscope (basophilic stippling). Signs and symptoms of chronic arsenic intoxication include mucosal irritation; darkening and thickening of the skin; liver injury; and peripheral vascular disease.
}

discussed in this report is based on preliminary evaluations of limited data. Considering the lack of data concerning 1-BP exposure and possible human health effects, and while further data are being collected, NIOSH investigators believe that occupational exposure to 1-BP should be minimized. As more data are gathered concerning recommended exposure guidelines for 1-BP, it is reasonable to use the $25 \mathrm{ppm}$ guideline for inhalation exposure that has been suggested by some in industry and by the EPA. The following recommendations, some of which were made in the NIOSH letter of February 1, 2000, are made with the goal of minimizing both inhalation and dermal 1-BP exposure among Marx workers.

1. Marx should continue investigating the use of non-hydrocarbon solvent (water-based) adhesives. This may require experimentation with the flow of cushion parts within the fabrication areas, since the water-based adhesives do not set up as quickly as does the current adhesive used at Marx Industries. For example, instead of spraying a cushion piece with the 1-BP-based adhesive and then immediately affixing the next piece to the cushion as is done now, with a water-based adhesive it may be necessary to spray several cushion pieces with adhesive, wait a short time, and then add the next cushion piece once the adhesive achieves the desirable tackiness.

2. Marx should install engineering controls to effectively reduce air concentrations of 1-BP (and therefore exposure) in the workplace. As previously mentioned, spray booths with local exhaust ventilation that is discharged to the outside have been shown to adequately reduce 1-BP exposures. Design specifications for such spray booths and ventilation systems can be found in the book Industrial Ventilation, A Manual of Recommended Practice, $22^{\text {nd }}$ Edition by the ACGIH. ${ }^{36}$ After equipment such as spray booths are installed, it is important to note the following:

a. A routine maintenance program is necessary for engineering controls to function properly.

b. Marx should reevaluate employee exposures to 1-BP in the spray line areas after measures have been taken to reduce exposures. 
3. Marx should educate and train employees concerning possible health problems associated with 1-BP exposure and the importance of proper use of all equipment so that exposure to 1-BP is minimized.

4. In general, PPE is the least desirable method of exposure control. Engineering controls (\# 2 above) are recommended to decrease inhalation exposure of Marx employees to 1-BP. However, in some instances, manufacturers have used respiratory protection in workplaces where 1-BP is being used. If respirators are used for protection from inhalation exposures to 1-BP, NIOSH-approved air-purifying respirator with organic vapor cartridges should be used. Respirators should only be used in the context of a comprehensive respiratory protection program. This program should be consistent with the NIOSH recommendations and the enforceable requirements set forth in the OSHA Safety and Health Standards. ${ }^{37,38}$

5. For protection from dermal (skin) exposures to 1-BP, gloves and aprons made from flexible laminates (e.g. Viton ${ }^{\mathrm{TM}},{ }_{39,40}^{4 \mathrm{H}^{\mathrm{TM}}}$ (PE/EVAL), Silver Shield ${ }^{\mathrm{TM}}$ ) should be used.

6. Marx should consider the extent of 2-BP contamination when selecting a 1-BP-based adhesive. If 1-BP-based adhesives are used, those adhesives which have the minimum level 2-BP contamination should be selected for use.

7. Marx should remain up-to-date with ongoing development of guidelines concerning occupational exposure to 1-BP, and also with any regulatory activities occurring that concern the bromopropanes.

8. The findings of our medical survey do not by themselves indicate that medical follow-up is needed for any specific employees or groups of employees. However, employees who are experiencing health effects potentially related to the workplace should be evaluated by a healthcare provider who has experience with occupational or environmental health issues.

\section{REFERENCES}

1. NIOSH [1994]. Elements by ICP: Method 7300. In: Eller PM, Cassinelli ME, eds. NIOSH manual of analytical methods. 4th ed. Cincinnati, OH: U.S. Department of Health and Human Services, Public Health Service, Centers for Disease Control and Prevention, National Institute for Occupational Safety and Health, DHHS (NIOSH) Publication No. 94-113.

2. EPA Method 6010. World Wide Web. http://www.epa.gov/epaoswer/hazwaste/test/6xx x.htm. (August 30, 2001).

3. Axelson O and Hogstedt C [1994]. Chapter 52 - The health effects of solvents. In: Zenz C, Dickerson OB, and Horvath EP, eds. Occupational Medicine, $3^{\text {rd }}$ Edition. Mosby Publishers, St. Louis, MO. pp. 764-778.

4. Ward E, et al [1996]. Risk of low red or white blood cell count related to estimated benzene exposure in a rubberworker cohort (19401975). AJIM 29:247-257.

5. Bleecker ML [1998]. Chapter 47 - Toxic peripheral neuropathy. In Rom WN, ed., Environmental and Occupational Medicine, $3^{\text {rd }}$ Edition. Lippincott-Raven Press, Philadelphia, PA. Pp 697-707.

6. NIOSH [1992]. Recommendations for occupational safety and health: compendium of policy documents and statements. Cincinnati, $\mathrm{OH}$ : U.S. Department of Health and Human Services, Public Health Service, Centers for Disease Control and Prevention, National Institute for Occupational Safety and Health, DHHS (NIOSH) Publication No. 92-100.

7. ACGIH [2002]. 2002 TLVs ${ }^{\circledR}$ and BEIs ${ }^{\circledR}$ : threshold limit values for chemical substances and physical agents. Cincinnati, OH: American Conference of Governmental Industrial Hygienists.

8. CFR [1997]. 29 CFR 1910.1000. Code of Federal Regulations. Washington, DC: U.S. Government Printing Office, Office of the Federal 
Register.

9. Rozman KK and Doull J [2002]. Derivation of an occupational exposure limit (OEL) for npropyl bromide using an improved methodology. Applied Occup and Environ Hygiene 17(10):711716.

10. Ichihara G, Yu X, Kitoh J, Asaeda N, Kumazawa T, Iwai H, Shibata E, Yamada T, Wang H, Xie Z, Maeda K, Tsukamura H, Takeuchi Y [2000]. Reproductive Toxicity of 1BP, a Newly Introduced Alternative to Ozone Layer Depleting Solvents, in Male Rats. Tox Sci 54:416-423.

11. Kim H-Y, Chung Y-H, Jeong J-H, Lee Y-M, Sur G-S, Kang J-K [1999]. Acute and Repeated Inhalation Toxicity of 1-Bromopropane in Sprague Dawley Rats. J Occup Health 41:121128.

12. EPA [2002]. Unpublished draft document: Acceptable Industrial Exposure Limit for NPropyl Bromide.

13. NIOSH [2002]. Hazard Evaluations and Technical Assistance report: Custom Products, Inc., Mooresville, NC. Cincinnati, OH: U.S. Department of Health and Human Services, Public Health Service, Centers for Disease Control and Prevention; National Institute for Occupational Safety and Health, DHHS (NIOSH) Publication No. 98-153.

14. Stump D [2001]. An inhalation twogeneration reproductive toxicity study of 1-bromopropane in rats. Study No. WIL-380001. Ashland, OH: WIL Research Laboratories. Unpublished. (Study sponsored by Brominated Solvents Consortium [BSCO]).

15. Smith RL [2000]. Presentation titled "NPropyl Bromide" which was given on November 6, 2000, at a meeting between the U.S. Environmental Protection Agency and the Brominated Solvents Consortium.
16. Korean Ministry of Labour [2002]. Regulation on threshold limit values for chemical substances and physical agents. Announcement No. 2002-8. Korean Ministry of Labour, Seoul, Korea.

17. Park JS, Kim Y, Park DW, et al. [1997]. An outbreak of hematopoietic and reproductive disorders due to solvents containing 2bromopropane in an electronic factory, South Korea: epidemiological survey. J Occup Health 39:138-143.

18. Kim Y, Jung K, Hwan T, et al. [1996]. Hematopoietic and reproductive hazards of South Korean electronics workers exposed to solvents containing 2-bromopropane. Scand J Work Environ Health 22:387-391.

19. Ichihara G, Aseda N, Kumazawa T, et al. [1997]. Testicular and hematopoietic toxicity of 2-bromopropane, a substitute for ozone layer depleting chlorofluorocarbons. J Occup Health 39:57-63.

20. Kamijima M, Ichihara G, Yu X, et al. [1997]. Disruption of ovarian cyclicity due to 2-bromopropane in the rat. J Occup Health 39:3-4.

21. Yu IJ, Chung YH, Lim CH, et al. [1997]. Reproductive toxicity of 2-bromopropane in Sprague Dawley Rats. Scand J Work Environ Health 23:281-288.

22. Lim CH, Maeng SH, Lee JY, et al. [1997]. Effects of 2-bromopropane on the female reproductive function in Sprague Dawley rats. Ind Health 35:278-284.

23. Trump DL, Hochberg MC [1976]. Bromide Intoxication. Johns Hopkins Med J. 138(4):11923.

24. van Leeuwen FX, Sangster B [1987]. The toxicology of bromide ion. Crit Rev Toxicol. 18(3):189-213.

25. Eldan M, Carel RS, Factor-Litvak $P$, Goldsmith JR, Weitzman S [1996]. Biological 
Monitoring of Workers' Exposure to Bromine. JOEM. 38(10):1026-31.

26. Jones AR, Walsh DA [1979]. The oxidative metabolism of 1-bromopropane in the rat. Xenobiotica. 9(12):763-72.

27. Kawai T, Takeuchi A, Miyama Y, Sakamoto K, Zhang Z-W, Higashikawa K, Ikeda M [2001]. Biological monitoring of occupational exposure to 1-bromopropane by means of urinalysis for 1bromopropane and bromide ion. Biomarkers. 6(5):303-12.

28. Hanes FM, Yates A [1938]. An Analysis of Four Hundred Instances of Chronic Bromide Intoxication. South Med J. 31(6):667-71.

29. Ryan RP, Terry CE, Leffingwell SS. Toxicology Desk Reference. The Toxic Exposure and Medical Monitoring Index. $5^{\text {th }}$ edition. Volume 1: 1999-2000.

30. Lauwerys RR and Hoet P [2001]. Industrial Chemical Exposure: guidelines for biological monitoring. $3^{\text {rd }}$ Edition. CRC Press LLC, Boca Raton, Florida. pp. 202-218.

31. Smith TJ, Crecelius EA, and Reading JC [1977]. Airborne arsenic exposure and excretion of methylated arsenic compounds. Env Health Persp 19: 89-93.

32. EPA [2002]. EPA Announces Arsenic Standard For Drinking Water of 10 Parts per B i 11 i o n. A va ilable a t http://www.epa.gov/epahome/headline_110101. htm ; accessed February 18, 2003.

33. NIOSH [2002]. Hazard Evaluations and Technical Assistance report: STN Cushion Company, Thomasville, NC. Cincinnati, OH: U.S. Department of Health and Human Services, Public Health Service, Centers for Disease Control and Prevention; National Institute for Occupational Safety and Health. DHHS (NIOSH) Publication No. 2000-410.
34. Kawai T, Takeuchi A, Miyama Y, Sakamto K, Zhang ZW, Higashikawa K, Ikeda M [2001]. Biological monitoring of occupational exposure to 1-bromopropane by means of urinalysis for 1-bromopropane and bromide ion. Biomarkers 6(5):303-312.

35. ACGIH [2001]. Documentation of threshold limit values and biological exposure indices for chemical substances and physical agents. Cincinnati, OH: American Conference of Governmental Industrial Hygienists.

36. ACGIH [1996]. Industrial Ventilation. $22^{\text {nd }}$ ed., A Manual of Recommended Practice. Cincinnati, OH: American Conference of Governmental Industrial Hygienists.

37. NIOSH [1987]. NIOSH guide to industrial respiratory protection. Cincinnati, Ohio: U.S. Department of Health and Human Services, Public Health Service, Centers for Disease Control and Prevention, National Institute for Occupational Safety and Health, Publication No. 87-116.

38. OSHA [1998]. Respiratory protection. Title 29 Code of Federal Regulations Part 1910.134. Washington, DC. U.S. Department of Labor, Occupational Safety and Health Administration.

39. Ensolv MSDS. World Wide Web [URL=www.ensolv.com. ], August 27, 2001.

40. Albemarle MSDS. World Wide Web [URL= www.albemarle.com/abzuserman.htm ], June 21, 2002 . 
TABLE 1

Inhalation Exposure ${ }^{1}$ and Area Air Sampling Data for 1-BP and 2-BP, Marx Industries, Inc., HETA 99-0260-2906, November 17, 1999

\begin{tabular}{|c|c|c|c|c|}
\hline Job Title/Sample Type & Location & Sample Volume (L) & 1-BP (PPM) & 2-BP (PPM) \\
\hline Adhesive Sprayer & Glue Line & 24.4 & 105.9 & 0.32 \\
\hline Adhesive Sprayer & Glue Line & 24.5 & 89.2 & 0.25 \\
\hline Adhesive Sprayer & Glue Line & 24.7 & 77.3 & 0.23 \\
\hline Adhesive Sprayer & Glue Line & 24.2 & 131.4 & 0.35 \\
\hline Adhesive Sprayer & Glue Line & 24.2 & 115.0 & 0.33 \\
\hline Adhesive Sprayer & Glue Line & 24.6 & 66.3 & 0.22 \\
\hline Adhesive Sprayer & Glue Line & 24.1 & 57.7 & 0.19 \\
\hline Doffer & Glue Line & 23.4 & 51.8 & 0.16 \\
\hline Supervisor/Set-up & Glue Line & 23.1 & 18.1 & 0.08 \\
\hline Adhesive Sprayer & Springs Line & 23.1 & 86.1 & 0.24 \\
\hline Adhesive Sprayer & Springs Line & 23.6 & 160.0 & 0.43 \\
\hline Adhesive Sprayer & Springs Line & 23 & 121.0 & 0.32 \\
\hline Adhesive Sprayer & Springs Line & 22.7 & 253.9 & 0.68 \\
\hline Adhesive Sprayer & Springs Line & 22.6 & 123.1 & 0.35 \\
\hline Foam Set-up & Springs Line & 22.5 & 38.0 & 0.11 \\
\hline Doffer & Springs Line & 22.1 & 45.9 & 0.14 \\
\hline Area Air Sample & Focus Saw Area- Spring & 21.8 & 8.7 & 0.06 \\
\hline Area Air Sample & Cutting Area-Glue & 21.2 & 5.3 & $\mathrm{n} / \mathrm{a}^{2}$ \\
\hline Minimum Detectable Concentration & & $\mathbf{0 . 0 0 7}$ & $\mathbf{0 . 0 2}$ \\
\hline Minimum Quantifiable Concentration & & $\mathbf{0 . 0 5}$ \\
\hline
\end{tabular}

${ }^{1}$ Time weighted average exposures; ${ }^{2}$ Result not available 
TABLE 2

Descriptive Statistics for 1-BP Exposure Data

Marx Industries, Inc., HETA 99-0260-2906, November 17, 1999

\begin{tabular}{|c|c|c|}
\hline \multirow[t]{2}{*}{ Sample Set (Number $\left.{ }^{1}\right)$} & \multicolumn{2}{|c|}{ 1-BP Concentration ${ }^{2}$ Data } \\
\hline & $G M^{3}$ & Range \\
\hline All Exposure Data (16) & 81.2 & $18.1-253.9$ \\
\hline Glue Line Workers (9) & 69.8 & $18.1-131.4$ \\
\hline Glue Line Sprayers (7) & 88.4 & $57.7-131.4$ \\
\hline Springs Line Workers (7) & 98.6 & $38.0-253.9$ \\
\hline Springs Line Sprayers (5) & 139.1 & $86.1-253.9$ \\
\hline All Sprayers (12) & 107.6 & $57.7-253.9$ \\
\hline
\end{tabular}

${ }^{1}$ Number of full-shift, time-weighted average exposures in the given sample set.

${ }^{2}$ The numbers in these columns represent the geometric mean and range (minimum value - maximum value) for the 1-BP exposure concentrations in the given sample set. The concentration data are in units of parts per million (ppm).

${ }^{3}$ Geometric mean 
TABLE 3

Descriptive Statistics for 2-BP Exposure Data

Marx Industries, Inc., HETA 99-0260-2906, November 17, 1999

\begin{tabular}{|l|c|c|}
\multicolumn{2}{|c|}{ Sample Set (Number ${ }^{I}$ ) } & \multicolumn{2}{c|}{ 2-BP Concentration ${ }^{2}$ Data } \\
\cline { 2 - 3 } & GM & Range \\
\hline All Exposure Data (16) & $\mathbf{0 . 2 4}$ & $\mathbf{0 . 0 8 - 0 . 6 8}$ \\
\hline Glue Line Data (9) & 0.22 & $0.08-0.35$ \\
\hline Glue Line Sprayers (7) & 0.26 & $0.19-0.35$ \\
\hline Springs Line (7) & 0.28 & $0.11-0.68$ \\
\hline Springs Line Sprayers (5) & 0.38 & $0.24-0.68$ \\
\hline All Sprayers (12) & 0.31 & $0.19-0.68$ \\
\hline
\end{tabular}

${ }^{1}$ Number of full-shift, time-weighted average exposures in the given sample set.

${ }^{2}$ The numbers in these columns represent the geometric mean and range (minimum value - maximum value) for the 1-BP. exposure concentrations in the given sample set. The concentration data are in units of parts per million (ppm).

${ }^{3}$ Geometric mean. 
TABLE 4

1-BP and 2-BP Exposures ${ }^{1}$ for Unexposed Workers ${ }^{2}$

Marx Industries, Inc., HETA 99-0260-2906, January 29, 2001

\begin{tabular}{|c|c|c|c|c|c|}
\hline Job Title/Work Location & Sample \# & Sample time (min) & Sample volume (L) & 1-BP (ppm) & 2-BP (ppm) \\
\hline Maintenance & $\mathrm{m}-6$ & 430 & 21.6 & 3.1 & $\mathrm{nd}^{3}$ \\
\hline Office - cust. service & $\mathrm{m}-35$ & 461 & 46.7 & 3.0 & $\operatorname{trace}^{4}$ \\
\hline Office - cust. service & $\mathrm{m}-39$ & 463 & 46.9 & 3.3 & nd \\
\hline Office - accountant & $\mathrm{m}-49$ & 344 & 34.7 & 0.2 & nd \\
\hline Sew \& cut & $\mathrm{m}-15$ & 462 & 46.4 & 0.7 & nd \\
\hline Sew \& cut & $\mathrm{m}-18$ & 461 & 47.6 & 1.0 & nd \\
\hline Sew \& cut & $\mathrm{m}-19$ & 459 & 46.1 & 0.5 & nd \\
\hline Sewing & $\mathrm{m}-20$ & 356 & 35.6 & 0.4 & nd \\
\hline Supervisor - cut $\&$ sew & $\mathrm{m}-11$ & 438 & 44.3 & 0.4 & nd \\
\hline Fiber cutting - glue area & $m-45$ & 467 & 46.7 & 4.6 & trace \\
\hline Fiber cutting - glue area & $\mathrm{m}-43$ & 492 & 24.7 & 4.5 & nd \\
\hline Blowing & $\mathrm{m}-9$ & 425 & 42.9 & 0.1 & nd \\
\hline Blowing & $\mathrm{m}-10$ & 440 & 44.5 & 0.1 & nd \\
\hline Blowing & $\mathrm{m}-13$ & 441 & 44.4 & 0.5 & nd \\
\hline Blowing & $\mathrm{m}-14$ & 448 & 45.1 & 0.5 & nd \\
\hline Fiber cutting & $\mathrm{m}-44$ & 466 & 46.8 & 3.8 & trace \\
\hline Foam cutting & $\mathrm{m}-30$ & 467 & 47 & 1.3 & nd \\
\hline Foam cut above springs & $\mathrm{m}-38$ & 495 & 50.1 & 4.9 & trace \\
\hline Foam cutting & $\mathrm{m}-31$ & 470 & 47.3 & 1.0 & nd \\
\hline Foam cutting & $\mathrm{m}-8$ & 408 & 40.9 & 1.0 & nd \\
\hline
\end{tabular}


TABLE 4 Continued

1-BP and 2-BP Exposures ${ }^{1}$ for Unexposed Workers ${ }^{2}$

Marx Industries, Inc., HETA 99-0260-2906, January 29, 2001

\begin{tabular}{|c|c|c|c|c|c|}
\hline Job Title/Work Location & Sample \# & Sample time (min) & Sample volume (L) & 1-BP (ppm) & 2-BP (ppm) \\
\hline Foam cutting & $\mathrm{m}-27$ & 464 & 46.8 & 0.9 & nd \\
\hline Foam cutting & $\mathrm{m}-25$ & 477 & 47.5 & 2.0 & nd \\
\hline Foam cutting & $\mathrm{m}-28$ & 466 & 46.8 & 0.9 & nd \\
\hline Foam cutting & $\mathrm{m}-33$ & 439 & 44.1 & 1.2 & nd \\
\hline Foam cutting & $\mathrm{m}-4$ & 399 & 40 & 2.5 & nd \\
\hline Foam cutting & $\mathrm{m}-34$ & 477 & 48 & 3.0 & trace \\
\hline Foam cutting & $\mathrm{m}-29$ & 488 & 49.1 & 1.1 & nd \\
\hline \multicolumn{4}{|c|}{ Minimum Detectable Concentration } & 0.004 & 0.003 \\
\hline \multicolumn{4}{|c|}{ Minimum Quantifiable Concentration } & 0.01 & 0.01 \\
\hline
\end{tabular}

${ }^{1}$ Time-weighted average exposures.

${ }^{2}$ Unexposed workers defined by qualitative assessment of job duties as discussed in text.

${ }^{3} \mathrm{nd}=$ 'not detected'; for 2-BP nd exposures are below $0.003 \mathrm{ppm}$.

${ }^{4}$ trace $=2-\mathrm{BP}$ was detected but not in quantifiable amounts; trace exposures for 2-BP fall between $0.003-0.01 \mathrm{ppm}$. 
TABLE 5

1-BP and 2-BP Exposures ${ }^{1}$ for Unexposed Workers ${ }^{2}$

Marx Industries, Inc., HETA 99-0260-2906, January 29, 2001

\begin{tabular}{|c|c|c|c|c|c|c|}
\hline Job Title/Sample Type & Location & Sample \# & $\begin{array}{l}\text { Sample time } \\
\text { (minutes) }\end{array}$ & Sample volume (L) & 1-BP (ppm) & 2-BP (ppm) \\
\hline Springs area - no spraying & Springs Line & $\mathrm{m}-48$ & 497 & 24.9 & 10.7 & $\mathrm{nd}^{3}$ \\
\hline Supervisor & Springs Line & $\mathrm{m}-40$ & 503 & 50.6 & 21.4 & 0.04 \\
\hline Adhesive sprayer & Springs Line & $\mathrm{m}-42$ & 499 & 24.9 & 215.8 & 0.39 \\
\hline Adhesive sprayer & $\begin{array}{l}\text { Springs and } \\
\text { GlueLine }\end{array}$ & $m-26$ & 484 & 24 & 77.7 & 0.13 \\
\hline Adhesive sprayer & Springs Line & $\mathrm{m}-41$ & 496 & 24.9 & 280.5 & 0.52 \\
\hline Adhesive sprayer & Springs Line & $m-37$ & 426 & 25 & 70.6 & 0.13 \\
\hline Adhesive sprayer & $\begin{array}{l}\text { Springs and } \\
\text { GlueLine }\end{array}$ & $\mathrm{m}-47$ & 500 & 25.1 & 173.2 & 0.3 \\
\hline Adhesive sprayer & GlueLine & $\mathrm{m}-21$ & 477 & 24 & 115.2 & 0.2 \\
\hline Adhesive sprayer & GlueLine & $\mathrm{m}-5$ & 412 & 20.7 & 44.5 & 0.08 \\
\hline Adhesive sprayer & GlueLine & $\mathrm{m}-32$ & 481 & 24.1 & 38.0 & 0.06 \\
\hline Supervisor & GlueLine & $\mathrm{m}-22$ & 483 & 24 & 7.2 & $\operatorname{trace}^{4}$ \\
\hline Baler & GlueLine & $\mathrm{m}-24$ & 267 & 26.4 & 10.5 & 0.02 \\
\hline Baler & GlueLine & $\mathrm{m}-46$ & 493 & 49.3 & 19.9 & 0.03 \\
\hline \multicolumn{5}{|c|}{ Minimum Detectable Concentration } & 0.004 & 0.003 \\
\hline \multicolumn{5}{|c|}{ Minimum Quantifiable Concentration } & 0.01 & 0.01 \\
\hline
\end{tabular}

${ }^{1}$ time-weighted average exposures.

${ }^{2}$ Exposed workers defined by qualitative assessment of job duties as discussed in text.

${ }^{3} \mathrm{nd}=$ 'not detected'; for 2-BP nd exposures are below $0.003 \mathrm{ppm}$.

${ }^{4}$ trace $=2-\mathrm{BP}$ was detected but not in quantifiable amounts; trace exposures for 2-BP fall between $0.003-0.01 \mathrm{ppm}$. 
TABLE 6

Descriptive Summary Statistics for 1-BP Exposure (Tables 4 and 5)

Marx Industries, Inc., HETA 99-0260-2906, January 29, 2001

\begin{tabular}{|c|c|c|}
\hline \multirow[t]{2}{*}{ Sample Set (Number $\left.{ }^{1}\right)$} & \multicolumn{2}{|l|}{ 1-BP Concentration ${ }^{2}$} \\
\hline & Geometric Mean & Range \\
\hline All Monitoring Data (40) & 3.7 & $0.1-280.5$ \\
\hline Unexposed Workers (27) & 1.1 & $0.1-4.9$ \\
\hline Exposed Workers $(13)^{3}$ & 45.7 & $7.2-280.5$ \\
\hline Glue Line Sprayers (3) & 58.0 & $38.0-115.2$ \\
\hline Springs Line Sprayers (3) & 162.2 & $70.6-280.5$ \\
\hline Spring/Glue Line Sprayer (2) & 116.1 & $77.7-173.6$ \\
\hline All Sprayers (8) & 101.4 & $38.0-280.5$ \\
\hline
\end{tabular}

${ }^{1}$ Number of full-shift, time-weighted average exposures in the given sample set.

${ }^{2}$ The numbers in these columns represent the geometric mean and range (minimum value - maximum value) for the 1-BP exposure concentrations in the given sample set. The concentration data are in units of parts per million (ppm).

${ }^{3}$ Exposed workers included 8 sprayers and 5 other workers who were not actively spraying. 
TABLE 7

Descriptive Statistics for 2-BP Exposure

Marx Industries, Inc., HETA 99-0260-2906, January 29, 2001

\begin{tabular}{|c|c|c|}
\hline \multirow[t]{2}{*}{ Sample Set (Number $\left.{ }^{1}\right)$} & \multicolumn{2}{|c|}{ 2-BP Concentration ${ }^{2}$} \\
\hline & Geometric Mean & Range \\
\hline All Exposure Data (40) & $n / \mathbf{a}^{3}$ & $n d^{4}-0.52$ \\
\hline Unexposed Workers (27) & $\mathrm{n} / \mathrm{a}$ & nd - trace \\
\hline Exposed Workers $(13)^{5}$ & 0.066 & nd -0.52 \\
\hline Glue Line Sprayers (3) & 0.10 & $0.06-0.20$ \\
\hline Springs Line Sprayers (3) & 0.31 & $0.13-0.52$ \\
\hline Spring/Glue Line Sprayer (2) & 0.19 & $0.13-0.3$ \\
\hline All Sprayers (8) & 0.18 & $0.06-0.52$ \\
\hline
\end{tabular}

${ }^{1}$ Number of full-shift, time-weighted average exposures in the given sample set.

${ }^{2}$ The numbers in these columns represent the geometric mean and range (minimum value - maximum value) for the 1-BP exposure concentrations in the given sample set. The concentration data are in units of parts per million (ppm).

${ }^{3}$ value not calculated.

${ }^{4} \mathrm{nd}=$ not detected (concentration $<0.003 \mathrm{ppm}$ ); trace (concentration between $0.003-0.01 \mathrm{ppm}$ ).

${ }^{6}$ Spray line personnel included 8 sprayers and 5 other workers who were not actively spraying. 
TABLE 8

Description of Survey Participants by Qualitative Exposure Status ${ }^{1}$ Marx Industries, Inc., HETA 99-0260-2906

\begin{tabular}{||c|c|c|c|c|c|c|c|c||}
\hline & \multirow{2}{*}{$\begin{array}{c}\text { Female }(\%) \\
\end{array}$} & Age (Median) & $\begin{array}{c}\text { Median Time } \\
\text { (months) at } \\
\text { Current Job }\end{array}$ & \multicolumn{2}{|c|}{ Race \# (\%) } & $\begin{array}{c}\#(\%) \\
\text { Reporting } \\
\text { Past Use of } \\
\text { Alcohol }{ }^{2}\end{array}$ & $\begin{array}{c}\text { \# (\%) } \\
\text { Reporting } \\
\text { Current } \\
\text { Cigarette } \\
\text { Smoking }\end{array}$ & $\begin{array}{c}\text { PBZ Exposure to } \\
1-\mathrm{BP}^{3}(\mathrm{GM}, \\
\text { Range, in ppm) }\end{array}$ \\
\hline \hline $\begin{array}{c}\text { Exposed } \\
\text { (N=13) }\end{array}$ & $10(77)$ & 25 & 17 & $5(38)$ & $8(62)$ & $7(54)$ & $4(31)$ & $45.8(7-281)$ \\
\hline $\begin{array}{c}\text { Unexposed } \\
(\mathrm{N}=30)\end{array}$ & $14(50)$ & 37 & 27 & $19(68)$ & $9(32)$ & $13(46)$ & $8(29)$ & $1.1(0.1-5)$ \\
\hline
\end{tabular}

${ }^{1}$ All percentages are based on number of actual respondents.

$2 \#\left(\frac{\circ}{\circ}\right)$ of respondents reporting at least one drink of alcohol in month prior to the survey.

${ }^{3}$ Geometric mean 1-bromopropane personal breathing zone concentrations in parts per million from sampling performed during NIOSH HHE; statistically significant difference in 1-BP exposure between exposed and unexposed workers (p-value <.001). 
TABLE 9

Summary of Exposure Assessments by Exposure Status

Marx Industries, Inc., HETA 99-0260-2906

\begin{tabular}{|c|c|c|c|c|c|c|}
\hline & $\begin{array}{c}\text { 1-BP Air } \\
\text { Concentration } \\
\text { GM}^{1} \text { (range), in } \\
\text { ppm }\end{array}$ & $\begin{array}{c}\text { End-of-week Serum } \\
\text { Br } \\
\text { GM (range), in mg/dl }\end{array}$ & $\begin{array}{c}\text { Cross-week Serum } \\
\text { Br difference } \\
\text { Mean (range) }\end{array}$ & $\begin{array}{c}\text { End-of-week Urine } \\
\text { Br } \\
\text { GM (range), in } \\
\text { mg/dl }\end{array}$ & $\begin{array}{c}\text { Cross-week Urine } \\
\text { Br difference } \\
\text { Mean (range) }\end{array}$ & $\begin{array}{c}\text { Whole Blood Br } \\
\text { GM (range), } \\
\text { mg/dl }\end{array}$ \\
\hline $\begin{array}{c}\text { Exposed } \\
\text { (Qualitative) }\end{array}$ & $45.8(7,281)$ & $14.9(3,43.5)$ & $2.3(-3.2,7.5)$ & $151.8(27,595)$ & $131(-20,497)$ & $12.6(3.2,32.6)$ \\
\hline $\begin{array}{c}\text { Unexposed } \\
\text { (Qualitative) }\end{array}$ & $1.1(0.1,5)$ & $2.7(1.7,11)$ & $0.3(-0.9,1.9)$ & $28.5(15,151)$ & $3.6(-30,77)$ & 3.0(1.9,8.6) \\
\hline Total & $3.6(0.1,281)$ & $4.8(1.7,43.5)$ & $\begin{array}{c}1.0(-3.2 \\
7.5)\end{array}$ & $\begin{array}{c}46.5(15, \\
595)\end{array}$ & $\begin{array}{c}41.9(-30 \\
497)\end{array}$ & $\begin{array}{c}4.7(1.9, \\
32.6)\end{array}$ \\
\hline
\end{tabular}

${ }^{1}$ Geometric Mean. 
TABLE 10

Correlation of Biologic Measures of Exposure with Personal Breathing Zone 1-BP Air Concentrations

Marx Industries, Inc., HETA 99-0260-2906

\begin{tabular}{|l|l|l|l|l|l|l|}
\hline & $\begin{array}{l}\text { Start-of-Week } \\
\text { Serum Br }\end{array}$ & $\begin{array}{l}\text { End-of-Week } \\
\text { Serum Br }\end{array}$ & $\begin{array}{l}\text { Serum Br } \\
\text { Cross-Week } \\
\text { Difference }\end{array}$ & $\begin{array}{l}\text { Start-of-Week } \\
\text { Urine Br }\end{array}$ & $\begin{array}{l}\text { End-of-Week } \\
\text { Urine Br }\end{array}$ & $\begin{array}{l}\text { Urine Br } \\
\text { Cross-Week } \\
\text { Difference }\end{array}$ \\
\hline $\begin{array}{l}\text { Correlation } \\
\text { Coefficient }\end{array}$ & 0.78 & 0.88 & 0.37 & 0.61 & 0.67 & 0.55 \\
\hline \# Observations & 40 & 38 & 38 & 39 & 38 & 37 \\
\hline$p$ Value & $<0.01$ & $<0.01$ & 0.02 & $<0.01$ & $<0.01$ \\
\hline
\end{tabular}

${ }^{1}$ Biologic measures of Br with 1-BP air concentration using the Spearman correlation coefficient.

TABLE 11

Number of Participants with Specific Symptoms Grouped by Exposure Category, With Prevalence Ratio and $95 \%$ CI Marx Industries, Inc., HETA 99-0260-2906

\begin{tabular}{|c|c|c|c|c|c|c|c|}
\hline Exposure category & $\begin{array}{c}\text { Painful Tingling } \\
\text { \# }(\%) \text { Yes }\end{array}$ & $\begin{array}{l}\text { Tremor } \\
\text { \# }(\%) \text { Yes }\end{array}$ & $\begin{array}{l}\text { Headache }^{3} \\
\text { \# }(\%) \text { Yes }\end{array}$ & $\begin{array}{l}\text { Felt "Drunk" } \\
\text { \# (\%) Yes }\end{array}$ & $\begin{array}{c}\text { Excessive Fatigue }^{5} \\
\#(\%) \text { Yes }\end{array}$ & $\begin{array}{c}\text { Trouble } \\
\text { Concentrating } \\
\text { \# }(\%) \text { Yes }\end{array}$ & $\begin{array}{c}\text { Anxiety, Nervousness } \\
\#(\%) \text { Yes }\end{array}$ \\
\hline Exposed $(N=13)^{6}$ & $4(31)$ & $2(15)$ & $9(69)$ & $4(36)$ & $4(31)$ & $1(8)$ & $7(54)$ \\
\hline Unexposed $(\mathrm{N}=30)$ & $8(30)$ & $0(0)$ & $13(45)$ & $2(7)$ & $2(7)$ & $3(11)$ & $6(21)$ \\
\hline $\begin{array}{l}\text { Prevalence Ratio }{ }^{7} \\
\quad(95 \% \mathrm{CI})\end{array}$ & $1.0(0.4-2.8)$ & - & $1.5(0.9-2.7)$ & $4.9(1.0-23.0)$ & $4.2(0.9-19.9)$ & $0.7(0.1-6.3)$ & $2.6(1.1-6.2)$ \\
\hline
\end{tabular}

${ }^{1}$ Numbness (pins and needles feeling) in hands or feet within last 30 days.

${ }^{2}$ Tremor or shakiness within last 30 days.

${ }^{3}$ Headache within last 30 days.

${ }^{4}$ Felt "drunk or high" in the last 30 days (even if not using alcohol or drugs).

${ }^{5}$ Sleeping too much in the last 30 days.

${ }^{6}$ Qualitative assessment of exposure to 1-BP.

${ }^{7}$ Prevalence ratio and $95 \% \mathrm{CI}$ for prevalence of symptom among those exposed versus those unexposed. 
TABLE 12

Mean PBZ 1-BP Exposure Among Persons Reporting Presence/Absence of Symptoms in 30 Days Prior to the Survey Marx Industries, Inc., HETA 99-0260-2906

\begin{tabular}{|c|c|c|c|}
\hline Symptom & Response (Number) & GM 1-BP (ppm) & $\mathrm{p}$ value \\
\hline \multirow[t]{2}{*}{ Headache } & No $(\mathrm{N}=20)$ & 2.1 & \multirow[t]{2}{*}{0.04} \\
\hline & Yes $(\mathrm{N}=19)$ & 7.9 & \\
\hline \multirow[t]{2}{*}{ Abnormal Fatigue } & No $(\mathrm{N}=32)$ & 3.3 & \multirow[t]{2}{*}{0.2} \\
\hline & Yes $(\mathrm{N}=5)$ & 12.8 & \\
\hline \multirow[t]{2}{*}{ Problem Concentrating } & No $(N=34)$ & 3.7 & \multirow[t]{2}{*}{0.4} \\
\hline & Yes $(\mathrm{N}=4)$ & 8.9 & \\
\hline \multirow[t]{2}{*}{ Feel "Drunk" } & No $(N=29)$ & 2.1 & \multirow[t]{2}{*}{0.004} \\
\hline & Yes $(\mathrm{N}=6)$ & 25.8 & \\
\hline \multirow[t]{2}{*}{ Painful tingling in your hands or feet } & No $(\mathrm{N}=26)$ & 4.3 & \multirow[t]{2}{*}{0.9} \\
\hline & Yes $(\mathrm{N}=11)$ & 3.9 & \\
\hline \multirow[t]{2}{*}{ Tremor (shakiness) } & No $(\mathrm{N}=35)$ & 3.5 & \multirow[t]{2}{*}{0.08} \\
\hline & Yes $(\mathrm{N}=2)$ & 49.7 & \\
\hline \multirow[t]{2}{*}{ Anxiety, nervousness } & No $(\mathrm{N}=27)$ & 2.4 & \multirow[t]{2}{*}{0.02} \\
\hline & Yes $(\mathrm{N}=12)$ & 12.2 & \\
\hline
\end{tabular}

${ }^{1}$ Two-sample t-test, two sided.

${ }^{2}$ Positive response to the question: "Have you felt "drunk" when you have not been drinking?" 
TABLE 13

Median Value for Blood Count Test Results Among Participants in the Medical Survey, By Exposure Category Marx Industries, Inc., HETA 99-0260-2906

\begin{tabular}{|c|c|c|c|c|}
\hline Exposure Status ${ }^{1}$ & $\begin{array}{c}\mathrm{RBC}^{2} \\
\left(10^{6} \text { per } \mathrm{mm}^{3}\right)\end{array}$ & $\begin{array}{c}\text { Hemoglobin }{ }^{3} \\
\text { (grams per deciliter) }\end{array}$ & $\begin{array}{c}\text { WBC }^{4} \\
\left(10^{3} \text { per } \mathrm{mm}^{3}\right)\end{array}$ & $\begin{array}{c}\text { Platelets }{ }^{5} \\
\left(10^{3} \text { per } \mathrm{mm}^{3}\right)\end{array}$ \\
\hline Exposed $(\mathrm{N}=13)$ & 4.9 & 14.3 & 6.6 & 221 \\
\hline Unexposed $(\mathrm{N}=27)$ & 5 & 14.7 & 8.5 & 284 \\
\hline
\end{tabular}

Qualitative assessment of exposure status.

${ }^{2}$ Red blood cells; Normal range: $3.8-5.810^{6} / \mathrm{mm}^{3}$

${ }^{3}$ Normal range: 11.6 - 17.1 grams per deciliter

${ }^{4}$ White blood cells; Normal range: $3.9-11.410^{3} / \mathrm{mm}^{3}$

${ }^{5}$ Normal range: $140-40010^{3} / \mathrm{mm}^{3}$

TABLE 14

Exposure Measures and Individual Components of CBC, $\beta$ (slope) ${ }^{1}$ and p-value from Linear Regression Marx Industries, Inc., HETA 99-0260-2906

\begin{tabular}{|c|c|c|c|c|c|c|c|c|}
\hline \multirow[t]{2}{*}{ Exposure Measure } & \multicolumn{2}{|c|}{$\mathrm{RBC}^{2}$} & \multicolumn{2}{|c|}{ Hemoglobin $^{3}$} & \multicolumn{2}{|c|}{$\mathrm{WBC}^{4}$} & \multicolumn{2}{|c|}{ Platelets ${ }^{5}$} \\
\hline & $\beta$ & $\mathrm{p}$-value & $\beta$ & $\mathrm{p}$-value & $\beta$ & $\mathrm{p}$-value & $\beta$ & p-value \\
\hline $\begin{array}{c}\text { 1-BP PBZ } \\
\text { Concentration }\end{array}$ & -0.03 & 0.23 & -0.005 & 0.95 & -0.37 & 0.10 & -7.5 & 0.38 \\
\hline End-of-Week Urine Br & -0.019 & 0.7 & 0.03 & 0.9 & -0.67 & 0.08 & -11.5 & 0.45 \\
\hline
\end{tabular}

${ }^{1} \beta=$ parameter estimate (slope) from linear regression model.

${ }^{2}$ Red blood cells; Values adjusted for age, gender, and race.

${ }^{3}$ Values adjusted for age, gender, and race.

${ }^{4}$ White blood cells adjusted for age.

${ }^{5}$ Adjusted for age.

${ }^{6} 1-B P$ personal breathing zone concentration. 
TABLE 15

1-BP Exposure and Determination of Semen Analyses Among Participants in the Male Reproductive Evaluation Marx Industries, Inc., HETA 99-0260-2906

\begin{tabular}{|c|c|c|c|c|}
\hline Exposure Status & $\begin{array}{c}\text { 1-BP Exposure } \\
(\mathrm{GM} \text {, range [ppm]) }\end{array}$ & $\begin{array}{c}\text { End-of-Week Urine Br } \\
\text { GM (range mg/dL) }\end{array}$ & $\begin{array}{c}\text { \# with Abnormal } \\
\text { Semen Evaluation }\end{array}$ & $\begin{array}{c}\text { with Normal }{ }^{2} \\
\text { Semen Evaluation }\end{array}$ \\
\hline Exposed $(\mathrm{n}=3)$ & $19.9(10.5,70.6)$ & $54.1(27,110)$ & $1^{3}$ \\
\hline Unexposed $(\mathrm{n}=6)$ & $1.6(0.5,4.5)$ & $30.3(15.4,151)$ & $4^{4}$ \\
\hline
\end{tabular}

Qualitative assessment of exposure status.

${ }^{2}$ Qualitative assessment of semen analyses performed by NIOSH reproductive scientist.

${ }^{3}$ Including one person with decreased percentage of sperm with normal shape.

${ }^{4}$ Including one person with decreased sperm motility and three persons with decreased sperm motility, decreased percentage of sperm, and normal sperm shape.

TABLE 16

Exposure Measures and Individual Components of Sperm Analyses Among Participants in the Male Reproductive Evaluation

$\beta$ (slope) $^{1}$ and $p$-value from Linear Regression Marx Industries, Inc., HETA 99-0260-2906

\begin{tabular}{|c|c|c|c|c|c|}
\hline \multirow{2}{*}{\begin{tabular}{c} 
Exposure Measure \\
\cline { 2 - 6 }
\end{tabular}} & \multicolumn{2}{|c|}{ Sperm Number } & \multicolumn{2}{|c|}{ Sperm Shape } & \multicolumn{2}{c|}{ Sperm Motility } \\
\hline $\begin{array}{c}\text { 1-BP PBZ } \\
\text { Concentration }\end{array}$ & 15.6 & 0.4 & 0.97 & 0.6 & 2.8 \\
\hline End-of-Week Urine Br & 49.1 & 0.1 & 5.5 & 0.1 & 9.8 \\
\hline
\end{tabular}

${ }^{1} \beta=$ parameter estimate (slope) from linear regression model.

${ }^{2} 1-B P$ personal breathing zone concentration. 
TABLE 17

1-BP Exposure and End-of-week Urine Br Concentrations by Status of Nerve Conduction Testing Marx Industries, Inc., HETA 99-0260-2906

\begin{tabular}{|c|c|c|}
\hline Nerve Conduction Testing & $\begin{array}{c}\text { PBZ 1-BP Exposure } \\
\text { (GM, range [ppm] })\end{array}$ & $\begin{array}{c}\text { End-of-week urine Br concentration } \\
\text { (GM, range [mg/dl] })\end{array}$ \\
\hline Abnormal $(\mathrm{n}=5)$ & $2.6(0.1-21.4)$ & $35.5 \quad(17.5-58.4)$ \\
\hline Normal $(\mathrm{n}=37)$ & $4.2^{2}(0.2-280.5)$ & $48.8^{3}(15.4-595)$ \\
\hline
\end{tabular}

${ }^{1}$ Nerve conduction testing determined by the consulting physician to be normal (including 4 tests judged to be "borderline," 4 tests which were incomplete or with a minor technical difficulty, and 29 complete studies determined to be normal without qualification) or abnormal (including 1 determined to be 'probably' abnormal). ${ }^{2} \mathrm{p}$-value $=.07$, t-test.

${ }^{3} \mathrm{p}$-value $=.09$, Wilcoxon two-sample test.

TABLE 18

Summary of Urinary Inorganic Arsenic by Exposure Category Marx Industries, Inc., HETA 99-0260-2906

\begin{tabular}{|c|c|c|}
\hline Exposure category & $\begin{array}{c}\text { Arsenic Concentration Geometric Mean } \\
\text { (range) } \\
\mu g / g \text { creat }^{2}\end{array}$ & $\begin{array}{c}\#\left(\frac{\circ}{\circ}\right) \text { Persons with } \\
\text { Concentration above } 25 \mu \mathrm{g} / \mathrm{g} \\
\text { creat }{ }^{3}\end{array}$ \\
\hline Exposed $(\mathrm{N}=12)$ & $62.8(13,215)$ & $10(83 \%)$ \\
\hline Unexposed $\quad(\mathrm{N}=29)$ & $12.9(6,81)$ & $2(7 \div)$ \\
\hline
\end{tabular}

${ }^{1}$ Exposure category refers to qualitative exposure to $1-\mathrm{BP}$.

${ }^{2}$ Micrograms arsenic per gram of creatinine.

${ }^{3} 25 \mathrm{\mu g} / \mathrm{g}$ creat is the concentration of arsenic in urine used for this HHE as a cutoff above which some occupational or environmental exposure is suspected. 


\section{APPENDIX 1}

\section{1-Bromopropane}

\section{Background}

Bromopropanes are a class of brominated hydrocarbons that exist in 2 isomeric forms: 1-bromopropane (1-BP; CAS No. 106-94-5) and 2-bromopropane (2-BP; isopropyl Br; CAS No.75-26-3). Both isomers are volatile and believed to be less destructive to the ozone layer than chlorinated hydrocarbon solvents such as $1,1,1$-trichloroethane.

Although each compound possesses useful solvent properties, 2-BP has not been used commercially in the United States. Workplace epidemiological studies and animal toxicological studies conducted in South Korea, Japan, and China identified that 2-BP affects the organs of reproduction in males (low sperm count) and females (ovarian dysfunction), and also the hematopoietic (blood-forming) system. . $^{41,42,43,44,45,46,47,48} 1$-BP is currently marketed domestically and is being considered by the Environmental Protection Agency (EPA) as an alternative to chlorofluorocarbons (CFCs), a class of chemicals banned by international agreement for protection of the ozone layer. ${ }^{49}$

Workers exposed to 1-BP may be exposed to small (but measurable) quantities of 2-BP since the latter isomer is generated as a contaminant in the manufacture of the former. However, the percentage of 2-BP contamination in neat 1-BP has steadily decreased from $1-2 \%$ to $0.1 \%$ and below. ${ }^{50,51}$ A 1999 Occupational Safety and Health Administration (OSHA) analysis of several commercial samples of 1-BP found them to contain 2-BP in concentrations ranging from 0.1 $0.2 \% .{ }^{52}$ A voluntary consensus standard (D6368-02) published by ASTM International (formerly the American Society for Testing and Materials) covering vapor degreasing and general grade 1-BP specifies that the content of 2-BP in these solvent grades remain below $0.1 \%{ }^{53}$

The three industrial sectors currently using 1-BP that fall under the regulations of the EPA's Significant New Alternatives Policy program include the following: (1) non-aerosol solvent cleaning; (2) aerosols; and (3) adhesives, coatings, and inks. Within these sectors, 1-BP has a variety of end uses including metals cleaning, precision cleaning, electronics cleaning, aerosol solvents, and adhesives. Previous NIOSH Health Hazard Evaluations (HHEs) have been conducted in workplaces where employees have been exposed to 1-BP while using a cold vapor degreaser for the precision cleaning of electronic parts, and in two other plants where 1-BP was formulated as a solvent vehicle for spray adhesives. ${ }^{54,55,56}$ 1-BP may also be found as an intermediate in closed processes such as in the synthesis of pharmaceuticals, insecticides, quaternary ammonium compounds, flavors, or fragrances. ${ }^{57}$

In 1998, 645 tons of 1-BP were sold for use in Japan..$^{58}$ An article published in 1999 suggests that at that time more than 100,000 tons (200 million pounds) of brominated solvents were being produced annually in the United States alone. ${ }^{59}$ This likely represents an overestimation of both production and use by at least one order of magnitude. By contrast, in a report issued by the National Toxicology Program's Center for the Evaluation of Risks to Human Reproduction (NTP-CERHR), citing data provided by Enviro Tech International, Inc., 1.5 million pounds per year of 1-BP were produced in the United States, between 1999 
and 2000. ${ }^{57}$ During that same time, 2.8 million pounds of this chemical were imported into the US. More recently, the Brominated Solvents Consortium (BSOC) provided estimates of the annual global sales and emissions of 1-BP for solvent and adhesive applications: 10.6 million pounds in 2000, 6.9 million pounds in 2001, and 8.2 million pounds in 2002. The United Nations Environment Program n-Propyl Bromide (nPB) Task Force estimated current worldwide annual use and emissions of 1-BP at 11-22 million pounds. ${ }^{57}$

At present, there is no domestic production of 1-BP. Industry estimates are that between 2-2.5 million pounds are imported annually from Israel, Europe, and East Asia. ${ }^{51}$ The EPA reported that 6-8 million pounds per year are used as cleaning solvents or in cold vapor degreasers and between 1.1-7 million pounds per year are used in the formulation of adhesives. ${ }^{50}$

Most of the toxicologic information available concerning 1-BP is based on the results of laboratory animal studies. For example, the Albemarle Corporation, a producer of 1-BP, has developed its own recommended occupational exposure guideline for this chemical upon completion of a study of the effects of 1-BP exposure on reproduction in rats. As a result of their study, Albemarle proposed to other manufacturers and end-users a voluntary recommended exposure limit of $25 \mathrm{ppm}$ as an 8-hour TWA exposure. ${ }^{60}$ A contractor hired by the US EPA, using a mathematical model, has similarly developed a recommended occupational exposure limit of $25 \mathrm{ppm}$. This value was also based on the results of studies evaluating reproductive health effects in laboratory animals. Of the various organ systems reported to be affected by 1-BP, it has been suggested that the organs of reproduction may be the most sensitive.

The HHE at Marx Industries, however, was requested by the North Carolina Department of Labor as a result of reported neurological toxicity in workers at Marx Industries. Because of the nature of the HHE request and, since the reproductive and developmental effects of 1-BP exposure have already been comprehensively reviewed by the NTP-CERHR, ${ }^{57}$ this appendix will focus on reports concerned with the neurological toxicity of 1-BP exposure. This appendix will attempt to summarize available published English-language literature focusing on the effects of 1-BP exposure on the nervous system of both laboratory animals and humans. Unpublished studies concerning the toxicological effects of 1-BP exposure on laboratory animals were conducted by Clin Trial BioResearch (CTBR) and WIL Research Laboratories, Inc. These included a 28-day acute exposure, and a 13-week subchronic exposure study (both by CTBR), and a 2-generation toxicity study (by WIL Research Labs). Together, these three studies provide somewhat contradictory information concerning the neurological effects of exposure to 1-BP. The 13-week study identified impairment of gait and microscopic lesions to the brain and spinal cord that was not reproduced in the subchronic study. Similarly, the study conducted by WIL did not identify neurological effects that could be attributed to 1-BP exposure. These studies will not be addressed further within this appendix but will be integrated into an upcoming NIOSH Current Intelligence Bulletin.

\section{Effects of Acute and Chronic Exposure to 1-BP on Laboratory Animals}

An early study of the effects of 1-BP looked at both acute and chronic exposures to rats at varying levels of exposure. In a study of acute inhalational exposure, two groups of rats (20 male and 20 female) were subdivided into four groups of five rats each and exposed to 1-BP at doses of 11,000, 13,000, 15,000 and 17,000 and $\mathrm{ppm} .{ }^{59}$ In addition, five male and five female rats served as "control" animals and were not exposed to 1-BP.

Within an hour after experiment onset, the animals exposed to 1-BP developed lacrimation (watery eyes), piloerection (hair standing on end), ataxia (difficulty with balance and walking), "decreased activity," and a decreased response to auditory stimuli. Thus, early on, there was an indication that 1-BP may possess 
some neurotoxic properties. Two of five male rats that were exposed to 1-BP at 15,000 ppm died within 6 hours following exposure; four of five female rats exposed to the same concentration of 1-BP were dead within 24 hours following exposure. The authors reported no deaths of rats exposed to 1-BP at 17,000 ppm. In addition, there were no reports of seizure activity among the test animals.

The same research group also studied the effects of chronic 1-BP exposure on rats. For this part of the study, Kim and colleagues subdivided two additional groups of rats (40 male and 40 female) into four groups of 10 rats each. Each subgroup inhaled 1-BP at doses of 0, 50, 300, or 1800 ppm for 6 hours a day, 5 days a week for 8 weeks. Effects were noted only in those rats exposed to 1800 ppm of 1-BP and included "mild ataxia," and "decreased activity." These effects were neither permanent nor particularly long-lasting, resolving each day within approximately 1 hour following termination of exposure. ${ }^{59}$

In another study of the effects of chronic inhalational exposure, Ichihara and colleagues divided male rats into four groups and exposed them to 1-BP at concentrations of $0,200,400$, or 800 ppm for 8 hours a day for 12 weeks. ${ }^{61}$ Those rats exposed to airborne concentrations of 0,200 and 400 ppm developed no difficulties with their balance or their ability to walk. Those rats exposed to airborne concentrations of 800 ppm developed weakness in their hind limbs and consequently could not maintain their position on an inclined surface. The authors of this study did not, however, clearly state when these observed effects appeared relative to the initiation of the experiment.

\section{Effects of Acute and Chronic Exposure to 1-BP on the Peripheral Nervous System of Laboratory Animals}

\section{Limb Strength}

In the study of chronic inhalational exposure to 1-BP described above, Ichihara and colleagues exposed male rats to 1-BP at concentrations of 0, 200, 400, or $800 \mathrm{ppm}$ for 8 hours per day for 12 weeks. ${ }^{61}$ During the course of the 12 weeks, the rats were monitored for clinical signs of neurological effects. After 4 weeks, rats exposed to 1-BP at $200 \mathrm{ppm}$ exhibited a decrease in hind limb grip strength that then resolved spontaneously. By the end of the experiment (12 weeks) rats exposed to 1-BP at $400 \mathrm{ppm}$ were reported to exhibit a significant decrease in hind limb strength (as compared to controls). The $800 \mathrm{ppm}$ exposure group showed a transient increase in hind limb grip strength at 4 weeks before exhibiting a significant decrease in hind limb grip strength at 8 and at 12 weeks. Fore limb grip strength was also reported to decrease during the exposure period. Beginning at 8 weeks of exposure, rats exposed to concentrations of 400 ppm or greater exhibited a statistically significant dose-dependent fore limb weakness (as compared to controls) that became progressively worse during the exposure period.

Yu and colleagues identified neurological effects in their animals similar to those of Ichihara. ${ }^{49,62}$

In the study by Yu of chronic inhalational toxicity, male rats were either unexposed to 1-BP or were exposed at a dose of $1000 \mathrm{ppm}$ for 8 hours a day for a period up to 7 weeks. (Rats were also exposed to 2-BP at 100 and 1000 ppm in this study.) During the fifth week of exposure, six out of nine rats exposed to 1-BP at $1000 \mathrm{ppm}$ began to walk with a "paddle-like" gait. This was described as a dragging of the animal's hind limbs along the ground with the plantar surface of the hind paw turned upwards. The most severely affected animals moved by using their forelimbs despite the paralysis of hind limbs. At 6 weeks, the remaining three out of nine rats exposed to 1-BP showed the same signs of hind limb paralysis. As compared to the Ichihara study of chronic inhalational 
exposure, no forelimb weakness was reported. This may possibly be due to the overall length of exposure; the animals studied by Ichihara did not show signs of statistically significant forelimb weakness until 8 weeks of exposure, although weakness of forelimb grip strength was evident by 4 weeks.

\section{Nerve Conduction Studies}

Ichihara and colleagues, and Yu and colleagues also measured motor nerve conduction velocity (MCV) and distal latency (DL) in their animal populations exposed to 1-BP. Both teams found evidence of demyelination (slowing of the MCV and a lengthening in the DL) with increases in either the concentration of or duration of exposure to 1-BP. Ichihara reported that the effects on MCV and DL were not seen in either group of animals exposed to 1-BP at 200 ppm or $400 \mathrm{ppm}$, but became evident among animals exposed at $800 \mathrm{ppm}^{61}$

Yu and colleagues found MCV values slowed considerably and DL values became significantly prolonged as compared to control animals after 4 weeks of exposure to 1-BP at levels of $1000 \mathrm{ppm}^{49,62}$ This same research group noted that the onset of decrease in MCV and prolongation in DL occurred earlier in those rats exposed to 1 -BP at $1000 \mathrm{ppm}$ than in those exposed to $2-\mathrm{BP}$ at $1000 \mathrm{ppm}^{49}$

Zhao and colleagues conducted a study in which male rats received daily subcutaneous injections of 1-BP ( 5 days a week for 4 weeks) at doses reported by the authors to correspond to inhalational exposure levels of 300 and $1000 \mathrm{ppm}^{63}$ Although it is unclear that these injections accurately approximated inhalational exposures, the results of this study also showed slowing of MCV and prolongation of DL. Beginning at 2 weeks after experiment onset, the MCV began to slow (non-significantly) in a dose-dependent fashion. At 4 weeks after experiment onset, the observed differences between control animals and those exposed to 1-BP at the inhalational equivalent of $1000 \mathrm{ppm}$ became statistically significant. The MCV of those animals exposed to 1-BP at the inhalational equivalent of $300 \mathrm{ppm}$ did not slow significantly as compared to the control population. The DL in the peripheral nerves of rats exhibited significant and dosedependent prolongation as compared to controls. These results were consistent with those reported by Ichihara and Yu.

\section{Studies of Microscopic Pathology}

Ichihara and Yu also conducted light microscopic examinations of various peripheral nerves in animals with chronic inhalational exposure to 1-BP. Ichihara identified changes to the myelin sheaths of the peripheral nerves ("ovoid or bubble-like debris") and also to the arrangement of striated muscle fibers in muscles of the lower limb (soleus muscle). ${ }^{61}$ These changes were found only in the group with the highest level of exposure to 1-BP (800 ppm) and not at 0, 200, or $400 \mathrm{ppm}$. Yu reported similar changes to the myelin sheaths of the peripheral nerves of the rats in his study. The animals in the study by Yu received exposures of 1000 ppm..$^{49,62}$

Ichihara and colleagues also examined peripheral nerve and muscle tissue under the electron microscope in rats chronically exposed to 1-BP. At higher resolution, they confirmed the findings made using the light microscope. Alterations in the structure of the myelin sheath and in the regular pattern of striated muscle fibers was seen in animals exposed to $1-\mathrm{BP}$ at $800 \mathrm{ppm}^{61}$ 
As with the previous studies, Sohn and colleagues also exposed rats to increasing levels of 1-BP: 200, 500, and 1250 ppm for 6 hours a day, 5 days a week, for 13 weeks. ${ }^{64}$ Following exposure, animals were sacrificed and tissues from the central (brain and spinal cord) and peripheral (sacral and peroneal nerves) nervous systems were examined by light and electron microscopy. Unlike Ichihara and Yu, however, Sohn and colleagues found no statistically significant differences between a control group of rats (no exposure to 1-BP) and any of the experimental groups in terms of weight gain, food consumption, behavior, or activity. In addition, they found no evidence of neuronal damage in the cerebral gray matter, or demyelination in the white matter of the CNS, or any abnormal findings of the myelin that characterized the microscopy studies of Ichihara and Yu. Sohn and colleagues reported that the myelinated fibers in all study groups displayed uniform thickness throughout the length of the nerve.

\section{Effects of Acute and Chronic Exposure to 1-BP on the Central Nervous System of Laboratory Animals}

\section{Studies of Microscopic Pathology}

The studies conducted by Ichihara and colleagues and by Yu and colleagues provided evidence that chronic exposure to high doses of 1-BP in rats may also result in central nervous system pathology. Both authors report swelling and other cellular changes in the gracilis nucleus, located in the spinal cord. ${ }^{61,62}$ Ichihara's findings were made both under the light microscope and the electron microscope. Examination of the gracilis nucleus under electron microscopy revealed an accumulation of "mitochondria, myelin-like debris, various sized vesicles, vacuolated mitochondria, and amorphous dense materials." ${ }^{\text {" }}$ Yu and colleagues also reported finding "shrinkage" of cells within the cerebellum, and Ichihara noted a decreased cerebral weight as compared to control animals. ${ }^{61,62}$

\section{Studies of Biochemical Pathology}

Two additional studies reported on the findings of biochemical alterations in the nervous system of rats exposed to 1-BP. In the first study, Wang and colleagues measured levels of gamma-enolase and beta S-100 proteins in rats exposed to 1-BP for 7 days, 8 hours per day at 200, 400, or 800 ppm. ${ }^{65}$ Gammaenolase is a protein specifically located within nerve cells (neurons) and beta S-100 protein is found only outside the nerve cells, within glial cells. (Glial cells provide support to the nerve cells.) In addition to gamma-enolase and beta S-100, the authors measured creatine kinase, glutathione, and non-protein sulfhydryl groups in various regions of the central nervous system including the cerebrum, cerebellum, brain stem, and lumbar enlargement of the spinal cord. In rats exposed to 1-BP at $400 \mathrm{ppm}$ for 7 days, there was a decrease in measured gamma-enolase levels in both the cerebrum and cerebellum; at 800 ppm, total glutathione, nonprotein sulfhydryl groups, and gamma-enolase levels decreased in those same regions of the brain. The other measured markers (for example, beta S-100 protein) either did not change significantly or showed an inconsistent pattern throughout the central nervous system following 1-BP exposure. The authors postulate that the decrease in gamma-enolase may be due to one of two causes: either a decrease in total amounts of the enzyme per cell, or a decrease in the total number of neurons. The authors further conjecture that the decreases in gamma-enolase levels are specific for exposure to 1-BP, that they may indicate a mechanism of putative neurotoxicity, and that they occur sooner than do any obvious morphological changes within the nervous system.

Of interest is the concomitant decrease of glutathione and nonprotein sulfhydryl groups within the cerebrum and cerebellum of the test laboratory animals. Glutathione helps in the detoxification of various chemicals that enter the body. Conjugation with glutathione (and, possibly other sulfhydryl-containing molecules) represents a potential pathway of metabolism for 1-BP. ${ }^{66}$ Wang and colleagues, in their discussion of this research, suggest that with an increasing 
body burden of 1-BP, one might expect to see a concomitant decrease in glutathione concentration as metabolism exceeds the body's ability to regenerate this molecule. In the absence of glutathione, then, the rat brain may be at risk for chemical injury.

In the second paper published by Wang concerning the biochemical changes in the nervous system of rats exposed to 1-BP, the authors examined the effects of a more prolonged duration of exposure. ${ }^{67}$ In this second study, rats were exposed to 1-BP for 12 weeks, 7 days per week, 8 hours per day at 200, 400, or $800 \mathrm{ppm}$. The same biochemical parameters were measured in the same regions of the central nervous system as were described in the first study by Wang. In rats exposed to 1-BP for 12 weeks at 400 and 800 ppm there was a decrease in measured gamma-enolase levels in the cerebrum, however, not in the cerebellum as was the case in the short-term exposure study. Wang and colleagues hypothesize that the decrease in cerebellar gamma-enolase measured in the 7-day study may have represented only a transient effect of 1-BP in that area of the brain. Following 12 weeks of exposure to 1-BP at 800 ppm, glutathione levels decreased significantly in the cerebrum, cerebellum, and brainstem. And, as in the initial 1-week exposure study conducted by this group, the other measured markers either did not change significantly or showed an inconsistent pattern throughout the central nervous system following 1-BP exposure.

\section{Studies of Neurochemistry}

Three articles published by Fueta and colleagues concern the effects of 1-BP exposure on the neurochemistry of the rat brain, specifically in the region of the hippocampus. ${ }^{68,69,70}$ In the first two studies, rats were divided into groups that were exposed to 1-BP at 1500 ppm for 6 hours a day, 5 days a week for 1, 3, and 4 weeks. In the final study, rats were exposed to 1-BP at 700 ppm for 6 hours a day, 5 days a week for 8 weeks. Taken together, these studies suggest that beginning at 1 week post-exposure to 1-BP, there is a decrease in levels of inhibitory neurotransmitters around the hippocampus. Inhibitory neurotransmitters are responsible for regulating the flow of neurological impulses in the brain; in the absence of inhibitory neurotransmitters, abnormal behavior, movement disorders, and seizures may result. Fueta and colleagues are conducting studies to further elucidate the cellular and biochemical mechanisms by which inhibitory neurotransmitter levels may decrease in response to 1-BP exposure; they are beyond the scope of this review.

\section{Case Reports of Occupational Exposure to 1-BP}

In a case report by Sclar, ${ }^{71}$ a 19 year old male developed multiple medical complaints following a two-month exposure to an industrial solvent mixture. Used for degreasing parts, the solvent mixture contained 1-BP as the primary component but also contained butylene oxide, 1,3-dioxolane, nitromethane and "other components." The worker was responsible for dipping parts, by hand, into the solvent mixture and consequently had repeated daily dermal exposure to his dominant (right) hand. Quantification of exposure (dermal or inhalational) was notavailable. Over the course of his two month exposure, the worker developed weakness to both lower extremities as well as to his right hand. In addition, it is reported that he developed "numbness," dysphagia (difficulty swallowing), and unspecified urinary difficulties. Although the worker underwent an MRI scan and extensive nerve conduction studies, the nature of his "numbness," dysphagia, and urinary difficulties was not well characterized in the report.

Nerve conduction studies did, however, show evidence of a primary, symmetric, demyelinating polyneuropathy. The worker exhibited bilateral slowing of motor nerve conduction velocities and prolongation of the distal motor latencies in his lower extremities (legs). This finding is consistent with the laboratory animal studies described previously. Electromyelography of muscles in the legs revealed denervation and muscular wasting. In addition to the abnormalities 
found in the motor nerves, this man also showed "marked slowing" of the lower extremity sensory nerve conduction velocities. Based on the interpretation of the study results, the pathological process appeared to be located in the myelin sheath of the nerve as opposed to the nerve axon. The studies of the motor and sensory nerves of the upper extremities in this gentleman revealed that they were apparently spared. Nerve conduction velocities, motor evoked response amplitudes and measures of the time required for a nerve impulse to travel from the periphery to spinal cord and back were all within normal limits for the upper extremities.

Finally, this worker also had evidence (by MRI scan and somatosensory evoked potential studies) of lesions to the myelinated areas of the central nervous system (brain and spinal cord). The animal studies by Ichihara showed evidence of myelin pathology in the central nervous system of rats chronically exposed to 1-BP. It should be noted that other components of the industrial solvent mixture used by this worker have been reported as putative neurotoxins (butylene oxide and nitromethane) ${ }^{72,73}$ Moreover, without adequate characterization of the nature of this worker's exposure, it is difficult to attribute his health effects specifically to 1-BP. Nonetheless, when considered in light of the results of the previously described animal studies, this report suggests that 1-BP may exhibit potent neurotoxic effects at sufficiently elevated levels of exposure.

In a second case report, ${ }^{74}$ the authors describe clinical syndromes of three women who worked for companies producing foam cushions for the furniture industry in North Carolina. All three applied spray adhesive to foam cushions using a compressed air spray gun; the primary solvent vehicle in the adhesive was reported to be 1-BP. Although a unique constellation of symptoms was reported for each of the workers, their clinical syndromes had some similarities, including reports of staggering gait, numbness and paresthesias in the lower extremities (and in two workers extending to the perineum, hips, and back), vertigo or dizziness, and a variety of other symptoms. Two of the three workers developed peak symptoms consisting primarily of inability to walk, on the same day in June 2000. The third worker was also reported to have peak symptoms (including reported staggering gait) in June 2000, although the date was not specified. Physical examinations of the workers were essentially normal except for the following: (1) unsteady gait noted in one of the three workers (one worker was noted to have a normal gait and the gait examination was not reported for the third worker) and (2) decreased sensation to pin prick and decreased vibration sense in all three workers, with differing distributions for each worker. Notable portions of the physical examinations for the three workers included alert (clear) sensoria, normal reflex examinations, and normal muscle strength. Only one of the three workers had objective measures of peripheral neuropathy reported, and that testing was reported as within normal limits.

This case report included an assessment of exposure to 1-BP for one of the three workers, consisting of passive 1-BP sampling over a 6-day period four months after the worker presented with the reported clinical syndrome. That exposure assessment revealed an average TWA airborne exposure to 1-BP of 133 ppm (range: 60 - $261 \mathrm{ppm}$ ). The work histories of the three workers is not described completely in the paper. It was noted that the workers had variable amounts of time working with 1-BP-based glue - 11 months, 4 months, and 5 months. In summary, this second case report describes clinical syndromes, which include a component of neurologic symptoms, among three workers in a manufacturing facility that appears to be similar to Marx Industries. However, objective information which would be necessary to reach a conclusion concerning the nature of the reported clinical syndromes for these workers is not provided in the case report.

\section{Appendix 1 References}


41. Park J-S, Kim Y, Park DW, Choi KS, Park S-H, Moon Y-H [1997]. An Outbreak of Hematopoietic and Reproductive Disorders Due to Solvents Containing 2-Bromopropane in an Electronic Factory, South Korea: Epidemiological Survey. J Occup Health 39:138-143.

42. Kim Y, Jung K, Hwang T, Jung G, Kim H, Park J, Kim J, Park J, Park D, Park S, Choi K, Moon Y [1996]. Hematopoietic and reproductive hazards of South Korean electronic workers exposed to solvents containing 2-bromopropane. Scand J Work Environ Health 22:387-391.

43. Ichihara G, Aseda N, Kumazawa T, Tagawa Y, Kamijima M, Yu X, Kondo H, Nakajima T, Kitoh J, Yu I J, Moon Y H, Hisanaga N, Takeuchi Y [1997]. Testicular and Hematopoietic Toxicity of 2-Bromopropane, a Substitute for Ozone Layer-Depleting Chlorofluorocarbons. J Occup Health 39:57-63.

44. Yu IJ, Chung YH, Lim CH, Maeng SH, Lee JY, Kim HY, Lee SJ, Kim CH, Kim TG, Lim CH, Park JS, Moon YHet al. [1997]. Reproductive toxicity of 2-bromopropane in Sprague Dawley rats. Scand J Work Environ Health 23:281-288.

45. Kamijima M, Ichihara G, Kitoh J, Tsukamura H, Maeda K, Yu X, Xie Z, Nakajima T, Asaeda N, Hisanaga N, Takeuchi Y [1997]. Ovarian Toxicity of 2-Bromopropane in the Non-Pregnant Female Rat. J Occup Health 39:144-149.

46. Koh J-M, Kim C-H, Hong SK, Lee K-U, Kim YT, Kim OJ, Kim GS [1998]. Primary ovarian failure caused by a solvent containing 2-bromopropane. Eur J Endocrin 138:554-556.

47. Lim CH, Maeng SH, Lee JY, Chung YH, Kim TG, Park JH, Moon YH, Yu IJ [1997]. Effects of 2-Bromopropane on the Female Reproductive Function in Sprague-Dawley Rats. Ind Health 35:278-284.

48. Yu X, Kamijima M, Ichihara G, Li W, Kitoh J, Xie Z, Shibata E, Hisanaga N, Takeuchi Y [1999]. 2-Bromopropane Causes Ovarian Dysfunction by Damaging Primordial Follicles and Their Oocytes in Female Rats. Toxicol and Appl Pharmacol 159:185-193.

49. Yu X, Ichihara G, Kitoh J, Xie Z, Shibata E, Kamijima M, Takeuchi Y [2001]. Neurotoxicity of 2-BP and 1-BP, Alternative Solvents for Chlorofluorocarbons. Env Res Section A 85:48-52.

50. Sheppard M [2003]. Telephone conversation on March 7, 2003, between M. Sheppard, United States Environmental Protection Agency, and J. Nemhauser, Division of Surveillance, Hazard Evaluations and Field Studies, National Institute for Occupational Safety and Health, Centers for Disease Control and Prevention, Public Health Service, U.S. Department of Health and Human Services.

51. Morford R [2003]. Telephone conversation on March 11, 2003, between R. Morford, EnviroTech International, Inc., and J. Nemhauser, Division of Surveillance, Hazard Evaluations and Field Studies, National Institute for Occupational Safety and Health, Centers for Disease Control and Prevention, Public Health Service, U.S. Department of Health and Human Services. 
52. OSHA [1999]. Nomination of 1-bromopropane (1-BP) and 2-bromopropane (2-BP) for testing by the National Toxicology Program. Washington, DC: Department of Labor, Directorate of Health Standards Programs, U.S. Occupational Safety and Health Administration, DOL (OSHA).

53. ASTM International [2003]. D6368-02 Standard specification for vapor-degreasing grade and general grade normal-propyl bromide. West Conshohocken, PA: ASTM International.

54. NIOSH [2001]. Hazard evaluation and technical assistance report: Trilithic Inc., Indianapolis, IN. Cincinnati, OH: U.S. Department of Health and Human Services, Public Health Service, Centers for Disease Control and Prevention, National Institute for Occupational Safety and Health, DHHS (NIOSH) Publication No. 2000-0233-2845.

55. NIOSH [2002]. Hazard evaluation and technical assistance report: STN Cushion Company, Thomasville, NC. Cincinnati, OH: U.S. Department of Health and Human Services, Public Health Service, Centers for Disease Control and Prevention, National Institute for Occupational Safety and Health, DHHS (NIOSH) Publication No. 2000-0410-2891.

56. NIOSH [2002]. Hazard evaluation and technical assistance report: Custom Products, Inc., Mooresville, NC. Cincinnati, OH: U.S. Department of Health and Human Services, Public Health Service, Centers for Disease Control and Prevention, National Institute for Occupational Safety and Health, DHHS (NIOSH) Publication No. 98-0153-2883.

57. NTP [2002]. National Toxicology Program - Center for the Evaluation of Risks to Human Reproduction Report: Reproductive and Developmental Toxicity of 1-Bromopropane. Research Triangle Park, NC: U.S. Department of Health and Human Services, Public Health Service, National Institute of Environmental Health Sciences, National Toxicology Program, DHHS (NIEHS) Publication No. NTP-CERHR-1-BP-02.

58. Ichihara G, Yu X, Kitoh J, Asaeda N, Kumazawa T, Iwai H, Shibata E, Yamada T, Wang H, Xie Z, Maeda K, Tsukamura H, Takeuchi Y [2000]. Reproductive Toxicity of 1-BP, a Newly Introduced Alternative to Ozone Layer Depleting Solvents, in Male Rats, Tox Sci 54:416-23.

59. Kim H-Y, Chung Y-H, Jeong J-H, Lee Y-M, Sur G-S, Kang J-K [1999]. Acute and Repeated Inhalation Toxicity of 1-Bromopropane in Sprague Dawley Rats. J Occup Health 41:121-128.

60. Smith RL [2000]. Presentation titled "N-Propyl Bromide" which was given on November 6, 2000 at a meeting between the U.S. Environmental Protection Agency and the Brominated Solvents Consortium.

61. Ichihara G, Kitoh J, Yu X, Asaeda N, Iwai H, Kumazawa T, Shibata E, Yamada T, Wang H, Xie Z, Takeuchi Y [2000]. 1-Bromopropane, an Alternative to Ozone Layer Depleting Solvents, Is Dose-Dependently Neurotoxic to Rats in Long-Term Inhalation Exposure. Tox Sci 55: 116-123.

62. Yu X, Ichihara G, Kitoh J, Xie Z, Shibata E, Kamijima M, Asaeda N, Takeuchi Y [1998]. Short Communication: Preliminary Report on the Neurotoxicity of 1-Bromopropane, an Alternative Solvent for Chlorofluorocarbons. J Occup Health 40:234-5 
63. Zhao W, Aoki K, Xie T, Misumi J [1999]. Electrophysiological Changes Induced by Different Doses of 1-Bromopropane and 2-Bromopropane. J Occup Health 41:1-7.

64. Sohn Y-K, Suh J-S, Kim J-W, Seo H-H, Kim J-Y, Kim H-Y, Lee J-Y, Lee S-B, Han J-H, Lee Y-M, Lee J-Y [2002]. A histopathologic study of the nervous system after inhalation exposure to 1-bromopropane in rat. Toxicol Lett 131:195-201.

65. Wang H, Ichihara G, Ito H, Kato K, Kitoh J, Yamada T, Yu X, Tsuboi S, Moriyama Y, Sakatani R, Shibata E, Kamijima M, Itohara S, Takeuchi Y [2002]. Biochemical Changes in the Central Nervous System of Rats Exposed to 1-Bromopropane for Seven Days. Tox Sci 67: 114-120.

66. Jones AR and Walsh DA [1979]. The oxidative metabolism of 1-bromopropane in the rat. Xenobiotica 9(12):763-772.

67. Wang H, Ichihara G, Ito H, Kato K, Kitoh J, Yamada T, Yu X, Tsuboi S, Moriyama Y, Takeuchi T [2003]. Dose-Dependent Biochemical Changes in Rat Central Nervous System after 12-Week Exposure to 1-Bromopropane. NeuroToxicology 24:199-206.

68. Fueta Y, Ishidao T, Kasai T, Hori H, Arashidani K [2000]. Short Communication: Decreased Paired-pulse Inhibition in the Dentate Gyrus of the Brain in Rats Exposed to 1-Bromopropane Vapor. J Occup Health 42:149-51.

69. Fueta Y, Ishidao T, Arashidani K, Endo Y, Hori H [2002]. Hyperexcitability of the Hippocampal CA1 and the Dentate Gyrus in Rats Subchronically Exposed to a Substitute for Chlorofluorocarbons, 1-Bromopropane Vapor. J Occup Health 44:156-65.

70. Fueta Y, Fukunaga K, Ishidao T, Hori H [2002]. Hyperexcitability and changes in activities of $\mathrm{Ca}^{2+} / \mathrm{calmodulin}^{-d e p e n d e n t ~ k i n a s e ~ I I ~ a n d ~ m i t o g e n-~}$ activated protein kinase in the hippocampus of rats exposed to 1-bromopropane. Life Sciences 72:521-9.

71. Sclar G [1999]. Case Report: Encephalomyeloradiculoneuropathy following exposure to an industrial solvent. Clin Neurol and Neurosurg 101: 199-202.

72. Ohnishi A, Murai Y [1993]. Polyneuropathy due to ethylene oxide, propylene oxide, and butylene oxide. Environ Res 60(2):242-7.

73. Page EH, Pajeau AK, Arnold TC, Fincher AR, Goddard MJ [2001]. Peripheral neuropathy in workers exposed to nitromethane. Am J Ind Med $40(1): 107-13$.

74. Ichihara G, Miller JK, Ziolkowska A, Itohara S, and Takeuchi Y [2002]. Neurological disorders in three workers exposed to 1-bromopropane. Journal of Occupational Health $44: 1-7$. 


\section{APPENDIX 2}

TABLE 1

Data by Participant -Time-Weighted Average Personal Breathing Zone Air Concentrations of 1-BP, and Br Concentrations in Serum/Urine (start-and end-of-week samples) and Whole Blood HETA 99-0260-2906, Marx Industries, Inc.

January/February 2001

\begin{tabular}{|c|c|c|c|c|c|c|}
\hline Subject & $\begin{array}{c}1-\mathrm{BP} \\
(\mathrm{ppm})^{1}\end{array}$ & $\begin{array}{c}\text { Start-of-Week } \\
\text { Serum Br }\end{array}$ & $\begin{array}{c}\text { End-of-Week } \\
\text { Serum Br }\end{array}$ & $\begin{array}{c}\text { Start-of-Week } \\
\text { Urine Br }\end{array}$ & $\begin{array}{c}\text { End-of-Week } \\
\text { Urine Br }\end{array}$ & $\begin{array}{l}\text { Whole Blood } \\
\text { Br }\end{array}$ \\
\hline 1 & 3.1 & 1.7 & -3 & 5.3 & 18.9 & 3 \\
\hline 2 & 3.0 & 2.2 & 2.7 & 27 & 33.9 & 2.8 \\
\hline 3 & 3.3 & 1.7 & 2.0 & 30.5 & 18.6 & 2.5 \\
\hline 4 & 0.2 & 2.3 & - & 43.7 & 33.3 & - \\
\hline 5 & 0.7 & 1.4 & 3.3 & 1.2 & 34.6 & 3.4 \\
\hline 6 & 1.0 & 1.8 & 2.3 & 26 & 32.9 & 2.6 \\
\hline 7 & 0.5 & 2.5 & 2.4 & 51.3 & 42.2 & 3.1 \\
\hline 8 & 0.4 & 2.0 & 2.0 & 17.2 & 17.4 & 2.4 \\
\hline 9 & 0.4 & 2.4 & 2.0 & 64 & 34.5 & 2.7 \\
\hline 10 & 4.6 & 2.3 & 2.9 & 25.5 & 37.9 & 3.7 \\
\hline 11 & 4.5 & 10.8 & 11.1 & 73.7 & 150.9 & 8.6 \\
\hline 12 & 0.1 & 1.5 & 2.1 & 13.3 & 35.4 & 2.0 \\
\hline 13 & 0.1 & 1.4 & 1.7 & 14.0 & 21.4 & 1.9 \\
\hline 14 & 0.5 & 1.4 & 2.0 & 22.9 & 35.3 & 2.3 \\
\hline 15 & 0.5 & 2.2 & 2.0 & 17 & 15.4 & 2.4 \\
\hline 16 & 3.8 & 3.3 & 3.0 & 43.4 & 40.8 & 3.2 \\
\hline
\end{tabular}




\begin{tabular}{|c|c|c|c|c|c|c|}
\hline 17 & 1.3 & 1.6 & 2.3 & 17.1 & 28.7 & 2.7 \\
\hline 18 & 4.9 & 3.6 & 4.6 & 51.8 & 34.4 & 4.4 \\
\hline 19 & - & 3.7 & 2.8 & 26.7 & 15.4 & 2.9 \\
\hline
\end{tabular}

${ }^{1}$ parts per million

2all Br concentrations were milligrams per deciliter

${ }^{3}$ - indicates data not collected for that participant. 
Table 1 - Appendix 2 - cont.

\begin{tabular}{|c|c|c|c|c|c|c|}
\hline Subject & $\begin{array}{c}1-\mathrm{BP} \\
(\mathrm{ppm})^{1}\end{array}$ & $\begin{array}{c}\text { Start-of- } \\
\text { Week Serum } \\
\mathrm{Br}^{2}\end{array}$ & $\begin{array}{c}\text { End-of-Week } \\
\text { Serum Br }\end{array}$ & $\begin{array}{c}\text { Start-of- } \\
\text { Week Urine } \\
\text { Br }\end{array}$ & $\begin{array}{c}\text { End-of-Week } \\
\text { Urine Br }\end{array}$ & $\begin{array}{l}\text { Whole } \\
\text { Blood Br }\end{array}$ \\
\hline 20 & 0.9 & 2.6 & 2.2 & 27.3 & 28.6 & 2.7 \\
\hline 21 & -3 & - & - & 20.1 & 29.2 & - \\
\hline 22 & 3.0 & 2.2 & 3.1 & 28.6 & 29.3 & 3.0 \\
\hline 23 & 0.9 & 2.9 & 2.3 & 13.6 & 17.5 & 2.8 \\
\hline 24 & 1.1 & 1.9 & 3.0 & 19.4 & 35.8 & 3.4 \\
\hline 25 & 1.0 & 2.1 & 2.4 & 31.1 & 18.4 & 2.8 \\
\hline 26 & 1.2 & 3.6 & 3.6 & 25.9 & 34.7 & 3.5 \\
\hline 27 & 2.0 & 4.4 & 3.9 & 8.4 & - & 3.6 \\
\hline 28 & 2.5 & 2.7 & 2.6 & 19.4 & 16.2 & 2.8 \\
\hline 29 & - & 2.0 & - & 24.0 & 17.7 & - \\
\hline 30 & 1.0 & 1.8 & 2.5 & 27.0 & 33.6 & 2.6 \\
\hline $31^{4}$ & 70.6 & 10.1 & 14.7 & 19.2 & 53.1 & 11.4 \\
\hline 32 & 10.7 & 2.3 & 2.7 & 31.7 & 27.1 & 3.2 \\
\hline 33 & 77.7 & 14.9 & 16.9 & 55.3 & 204.3 & 14.8 \\
\hline 34 & 215.8 & 22.2 & 26.6 & 159.9 & 507.9 & 22.2 \\
\hline 35 & 19.9 & 9.0 & 9.3 & 66.1 & 46 & 7.6 \\
\hline 36 & 21.4 & 7.3 & 9.4 & 39 & 58.4 & 7.2 \\
\hline
\end{tabular}




\begin{tabular}{|c|c|c|c|c|c|c|}
\hline 37 & 7.2 & 5.7 & 5.6 & 59.7 & - & 5.8 \\
\hline 38 & 173.2 & 44.2 & 43.5 & 52.8 & 364.2 & 32.6 \\
\hline 39 & 38.0 & 13.3 & 17.3 & 174 & 238.9 & 14.9 \\
\hline 40 & 10.5 & 8.3 & 10.0 & 90.4 & 109.8 & 9.2 \\
\hline 41 & 44.5 & 20.7 & 28.0 & 225.5 & 332 & 21.6 \\
\hline 42 & 280.5 & 20.3 & 27.8 & 98.8 & 595.4 & 21.9 \\
\hline
\end{tabular}

${ }^{1}$ Parts per million

${ }^{2} \mathrm{All} \mathrm{Br}$ concentrations were milligrams per deciliter

3 -Indicates data not collected for that participant.

${ }^{4}$ Shaded area represents data from workers exposed to 1-BP (qualitative assessment). 
Appendix 2 - cont.

Table 2 - Data by Participant -Complete Blood Count Indices HETA 99-0260-2906, Marx Industries, Inc.

January/February 2001

\begin{tabular}{|c|c|c|c|c|}
\hline Subject & $\mathrm{RBC}^{1}$ & $\mathrm{HGB}^{2}$ & WBC $^{3}$ & $\mathrm{PLT}^{4}$ \\
\hline 1 & 4.95 & 14.9 & 7.76 & 319 \\
\hline 2 & 4.92 & 16.4 & 7.88 & 286 \\
\hline 3 & 5.04 & 13.6 & 10.65 & 295 \\
\hline 4 & -5 & - & - & - \\
\hline 5 & 5.06 & 14.7 & 10.52 & 204 \\
\hline 6 & 4.50 & 13.6 & 9.02 & 271 \\
\hline 7 & 4.53 & 13.8 & 9.48 & 464 \\
\hline 8 & 4.44 & 13.5 & 4.88 & 260 \\
\hline 9 & 4.76 & 13.9 & 9.94 & 290 \\
\hline 10 & 4.25 & 13.0 & 6.79 & 304 \\
\hline 11 & 5.49 & 15.9 & 6.36 & - \\
\hline 12 & 4.39 & 12.7 & 3.68 & 216 \\
\hline 13 & 4.10 & 12.3 & 8.91 & 290 \\
\hline 14 & 5.06 & 14.6 & 5.58 & 362 \\
\hline 15 & 5.26 & 15.9 & 11.78 & 264 \\
\hline 16 & 4.96 & 15.9 & 8.5 & 197 \\
\hline 17 & 5.07 & 15.2 & 8.73 & 186 \\
\hline
\end{tabular}




\begin{tabular}{|l|l|l|l|l|}
\hline 18 & 4.39 & 13.0 & 5.10 & 313 \\
\hline 19 & 5.04 & 14.9 & 8.11 & 199 \\
\hline 20 & 5.32 & 15.9 & 6.34 & 378 \\
\hline
\end{tabular}

${ }^{1}$ red blood cells, $10^{6}$ per cubic millimeter

${ }^{2}$ hemoglobin, grams per deciliter

${ }^{3}$ white blood cells, $10^{3}$ per cubic millimeter

${ }^{4}$ platelets, $10^{3}$ per cubic millimeter

5- indicates data not collected for that participant. 
Appendix 2 - cont.

\begin{tabular}{|c|c|c|c|c|}
\hline Subject & $\mathrm{RBC}^{1}$ & $\mathrm{HGB}^{2}$ & WBC $^{3}$ & $\mathrm{PLT}^{4}$ \\
\hline 21 & - & - & - & - \\
\hline 22 & 4.78 & 14.0 & 9.20 & 282 \\
\hline 23 & 5.20 & 14.4 & 10.90 & 356 \\
\hline 24 & 5.03 & 15.1 & 5.91 & 254 \\
\hline 25 & 5.27 & 15.6 & 6.37 & 238 \\
\hline 26 & 5.58 & 15.7 & 6.48 & 223 \\
\hline 27 & 4.94 & 14.6 & 10.5 & 457 \\
\hline 28 & 5.25 & 15.5 & 9.28 & 251 \\
\hline 29 & - & - & - & - \\
\hline 30 & 5.04 & 15.4 & 12.20 & 491 \\
\hline $31^{6}$ & 4.92 & 15.5 & 5.51 & 221 \\
\hline 32 & 5.49 & 16.1 & 4.3 & 295 \\
\hline 33 & 4.45 & 13.1 & 10.20 & 363 \\
\hline 34 & 4.54 & 12.9 & 8.56 & 211 \\
\hline 35 & 4.91 & 14.0 & 9.46 & 478 \\
\hline 36 & 4.89 & 14.9 & 6.55 & 152 \\
\hline 37 & 4.59 & 12.8 & 10.16 & 263 \\
\hline 38 & 5.26 & 15.4 & 7.04 & 149 \\
\hline
\end{tabular}




\begin{tabular}{|c|c|c|c|c|}
\hline 39 & 5.10 & 14.7 & 10.89 & 206 \\
\hline 40 & 5.06 & 14.3 & 6.07 & 215 \\
\hline 41 & 4.86 & 13.5 & 6.27 & 355 \\
\hline 42 & 4.27 & 13.0 & 3.91 & 257 \\
\hline 43 & 5.00 & 14.6 & 6.53 & 220 \\
\hline
\end{tabular}

${ }^{1}$ Red blood cells, $10^{6}$ per cubic millimeter

${ }^{2}$ Hemoglobin, grams per deciliter

${ }^{3}$ White blood cells, $10^{3}$ per cubic millimeter

${ }^{4} \mathrm{Platelets}, 10^{3}$ per cubic millimeter

${ }^{5}$-Indicates data not collected for that participant

${ }^{6}$ Shaded area represents data from workers exposed to 1-BP (qualitative assessment). 
To receive NIOSH documents or information about occupational safety and health topics contact NIOSH at:

$$
\begin{gathered}
\text { 1-800-35-NIOSH (356-4675) } \\
\text { Fax: 1-513-533-8573 } \\
\text { E-mail: pubstaff@cdc.gov } \\
\text { or visit the NIOSH web site at: } \\
\text { www.cdc.gov/niosh }
\end{gathered}
$$


